Prepared for the U.S. Department of Energy

under Contract DE-AC05-76RL01830

\title{
Demonstration of LED Retrofit Lamps at the Smithsonian American Art Museum, Washington, DC
}

NJ Miller

SM Rosenfeld

June 2012

\section{Pacific Northwest}

NATIONAL LABORATORY

Proudly Operated by Battelle Since 1965 


\title{
DISCIAIMER
}

This report was prepared as an account of work sponsored by an agency of the United States Government. Neither the United States Government nor any agency thereof, nor Battelle Memorial Institute, nor any of their employees, makes any warranty, express or implied, or assumes any legal liability or responsibility for the accuracy, completeness, or usefulness of any information, apparatus, produet, or process disclosed, or represents that its use would not infringe privately owned rights. Reference herein to any specific commercial product, process, or service by trade name, trademark, manufacturer, or otherwise does not necessarily constitute or imply its endorsement, recommendation, or favoring by the United States Government or any agency thereof, or Battelle Memorial Institute. The views and opinions of authors expressed herein do not necessarily state or rellect those of the United States Government or any agency thereof.

\author{
PACIFIC NORTHWFST NATIONAI, I.ABORATORY \\ operated by \\ BAT'TELLE \\ for the \\ INTTED STATES DEPARTMFNT OF ENFRGY \\ under Contract DE-AC05-76RL01830
}

Printed in the United States of America

Available to DOE and DOE contractors from the

Office of Scientific and Technical Information,

P.O. Box 62, Oak Ridge, TN 37831-0062;

ph: (865) 576-8401

fax: (865) 576-5728

email: reports@adonis.osti.gov

\author{
Available to the public from the National Technical Information Service, \\ U.S. Department of Commerce, 5285 Port Royal Rd., Springfield, VA 22161 \\ ph: (800) 553-6847 \\ fax: (703) 605-6900 \\ email: orders@ntis.fedworld.gov \\ online ordering: http://www.ntis.gov/ordering.htm
}

This document was printed on recycled paper.

(9/2003) 


\section{Demonstration of LED Retrofit Lamps at the Smithsonian American Art Museum, Washington, DC}

Final Report prepared in support of the U.S. DOE Solid-State Lighting Technology Demonstration GATEWAY Program

Study Participants:

Pacific Northwest National Laboratory

U.S. Department of Energy

The Smithsonian American Art Museum

NJ Miller ${ }^{1}$

SM Rosenfeld ${ }^{2}$

June 2012

Prepared for

the U.S. Department of Energy

under Contract DE-AC05-76RL01830

Pacific Northwest National Laboratory

Richland, Washington 99352

\footnotetext{
${ }^{1}$ Senior Lighting Engineer, Pacific Northwest National Laboratory, Portland, OR

${ }^{2}$ Lighting Designer, Smithsonian American Art Museum, Washington, DC
} 



\section{Preface}

This document is a report of observations and results obtained from a lighting demonstration project conducted under the U.S. Department of Energy (DOE) GATEWAY Solid-State Lighting (SSL) Technology Demonstration Program. The program supports demonstrations of high-performance SSL products in order to develop empirical data and experience with in-the-field applications of this advanced lighting technology. The GATEWAY Program focuses on providing a source of independent, third-party data for use in decision-making by lighting users and professionals; this data should be considered in combination with other information relevant to the particular site and application under examination. Each GATEWAY demonstration compares SSL products against the incumbent technologies used in that location. Depending on available information and circumstances, the SSL product may also be compared to alternate lighting technologies. Though products demonstrated in the GATEWAY Program have been prescreened for performance, DOE does not endorse any commercial product or in any way guarantee that users will achieve the same results through use of these products.

\section{Acknowledgements}

Scott Rosenfeld, Lighting Designer for the American Art Museum, provided access to his design process, evaluation results, and feedback from the Museum Director, Elizabeth Broun, and Chief Exhibit Designer, Claire Larkin, in addition to curators and other museum staff. Mr. Rosenfeld's photography of the exhibit spaces are used in this report. The Smithsonian Institution funded much of the experimental lamping and the time for Mr. Rosenfeld and his staff to evaluate dozens of different light-emitting diode (LED) replacement lamps. Much of the technical data of the preliminary lamp studies and comparisons was collected and organized by Marissa Baum and Kerry Beyer, interns at the American Art Museum. Lamp manufacturers have been generous with samples.

Jim Druzik of the Getty Conservation Institute and Steven Weintraub of Art Preservation Services generously shared their expertise on conservation issues. Their instruction and advice on properly assessing the damage potential of light allowed the Smithsonian American Art Museum to proceed confidently with the GATEWAY LED demonstration. 



\section{Executive Summary}

In the fall of 2010, Pacific Northwest National Laboratory contacted Scott Rosenfeld, Lighting Designer for the Smithsonian American Art Museum, to see if the Museum would be willing to participate in a GATEWAY demonstration project in which light-emitting diode (LED) replacement lamps would be used in exhibit space. At that time, the museum industry was concerned about increased damage potential from LEDs and other energy efficient lighting sources that produce a discontinuous spectrum. The Museum agreed to participate, based on a review of the existing literature conducted by Steven Weintraub of Art Preservation Services for the American Institute of Conservation, and subsequent testing of solid-state lighting sources on light sensitive materials performed by Jim Druzik of the Getty Conservation Institute.

Thus began the process, which lasted more than a year, of procuring lamp samples and performance data, testing them in the museum workshop, temporarily installing the lamps in one gallery for feedback, and ultimately replacing all traditional incandescent lamps in one gallery of modernist art at the American Art Museum and partially replacing lamps in two galleries of the Museum’s Renwick Gallery.

This report describes the selection and testing process, technology challenges, perceptions, economics, energy use, and mixed results of using LED replacement lamps in art galleries housing national treasures.

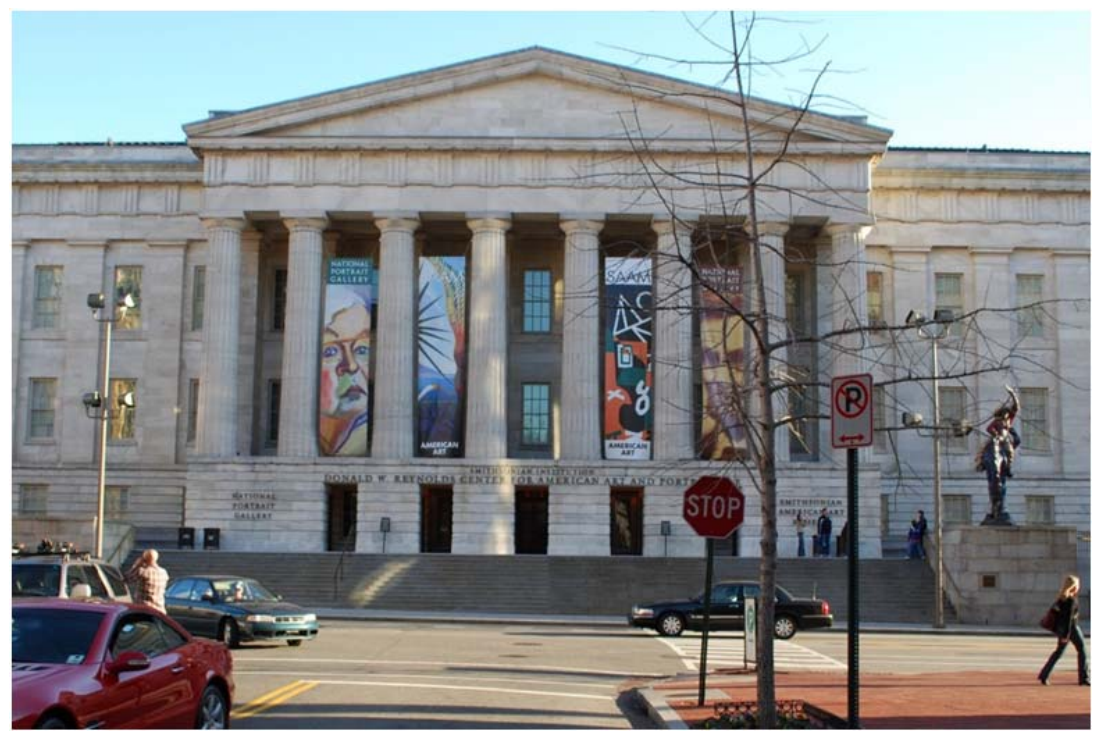

Figure ES.1. The Smithsonian American Art Museum in Washington, DC is a national historic landmark and features American art and portraiture. Photo courtesy of the Smithsonian American Museum of Art.

In evaluating LED alternatives for the GATEWAY project, the staff lighting designer found a wide variety of LED replacement lamps, many with excellent color and beam properties for display lighting and wallwashing techniques. These included PAR38 and PAR30 lamps. However, the museum's existing halogen lamps could not be replaced with LED lamps on a one-for-one basis because, although the two lamp types have similar beam characteristics, they differ in terms of intensity, color, and distribution. In addition, the LED lamps could not provide important beam angles offered by the 
museum's existing lamps, such as high intensity, very narrow beams $\left(4^{\circ}\right)$ that low-voltage incandescent lamps produce so well, nor were the LED lamps an effective substitute for the high lumen, high-intensity lamps used in very high ceiling galleries with long throw distances from track head to artwork.

Vertical illuminances in the museum's galleries range from 50 to 250 lux (5 to 25 footcandles [fc]) on the paintings and sculptures, including 25 to 60 lux (2.5 to $6 \mathrm{fc}$ ) of ambient light delivered to walls and floor. The museum has 7000 custom track heads that accept a range of incandescent lamp types and accessories, giving the designer the optical control to carefully set illuminance, distribution of light, and contrast between object and surroundings. The lighting designer's goal for the GATEWAY demonstration was to determine whether LED replacement lamps could help create the precise visual environment that makes the artwork visible and engaging, and evoke the color response that the museum director and curators desire to support the artistic intent, while saving energy and reducing cost and maintenance. The designer found that LED replacement lamps can provide a new palette of lamps with little compromise in aesthetic quality. However, it became clear that beam and color qualities cannot be determined simply by reviewing manufacturer literature, especially for blue and red hues. Different collections, media, and styles of art may call for different lamp color selections. There is still no substitute for visual judgment in selecting LED lamps.

The biggest challenge was replacing halogen MR16 lighting used in the Luce Foundation Center for American Art within the museum. The drivers built into LED MR16 replacement lamps are often incompatible with the electronic or magnetic transformer built into low-voltage track heads, especially when further complicated by a dimming control system. Flicker was a significant issue as were color and low light output, and as of this writing an ideal MR16 replacement product has not been found.

Power reductions were considerable in the galleries lamped with LEDs. Power use in the Early Modernism Gallery, which was completely relamped with 82 LED lamps, decreased from 3.9 watts per square foot $\left(\mathrm{W} / \mathrm{ft}^{2}\right)$ to $1.1 \mathrm{~W} / \mathrm{ft}^{2}$. Operation hours are 4500 per year in the museum galleries, and the new LED lighting in this single 1200 square foot gallery reduced electricity costs from $\$ 2,984$ to $\$ 816$ per year, recovering the higher initial cost of the LEDs in 16 months of operation through energy savings alone. In addition, spot-relamping frequency and cost (at \$7.20 per lamp for spot-relamping) were reduced considerably because of the LED's longer expected life. In a 10-year life cycle cost analysis including maintenance savings, at $\$ 0.14$ per $\mathrm{kWh}$ melded $^{1}$ electric rate, the total present value (PV) energy savings are $\$ 19,041$, with a total PV life-cycle cost savings of $\$ 27,891$.

Two areas of the Renwick Gallery showed similarly impressive energy savings, although their higher ceilings made it difficult to use all-LED lighting solutions.

\section{Follow-up LED Lamp Testing}

Six samples of each of three LED replacement lamp types used in the Early Modernism gallerySolais PAR30 $10^{\circ}$ SP lamps, Solais PAR30 $40^{\circ}$ flood (FL) lamps, and Optiled MR16 lamps-were sent to photometric laboratories for baseline testing. Two sample lamps of each of these three lamp types are scheduled to be removed from the installation and sent for photometric testing after 4000 hours, 8000 hours, and 12,000 hours. Although these are not the specific lamps originally tested for the baseline

\footnotetext{
${ }^{1}$ The melded (or blended) electric rate is the average rate charged by the utility per kilowatt-hour, including time-ofuse rate variations, demand charges, taxes, and fees.
} 
performance data, their average performance will be compared to the average original performance of that lamp type to document color and light output performance over time. These will be added to this report as they become available.

\section{Results of 4000 Hour Lamp Testing}

The follow-up tests showed that all three of the LED lamp types used in the Early Modernism gallery experienced changes over the year that this demonstration has been in place.

The testing showed that the two Solais $17 \mathrm{~W}$ PAR30 LED $10^{\circ} \mathrm{SP}$ lamps are very stable in terms of color and moderately stable in terms of light output. Their average lamp lumen output decreased by $6 \%$ from the average of the baseline tested lamps. Correlated color temperature (CCT) decreased by less than $7 \mathrm{~K}$ (negligibly warmer), color rendering index (CRI) decreased by less than 1 point, $\Delta \mathrm{u}^{\prime} \mathrm{v}^{\prime}$ varied by less than 0.0027 (less than a 3-step Macadam ellipse or less than 3 just-noticeable-differences), and watts decreased by $2 \%$.

The two Solais 17W PAR30 LED $40^{\circ} \mathrm{FL}$ lamps performed similarly after 4000 hours of operation. Their average lamp lumen output decreased by $8 \%$ from the average of the baseline tested lamps. CCT

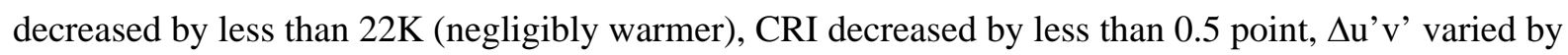
less than 0.00103 (less than a 1-step Macadam ellipse or less than 1 just-noticeable-differences), and watts decreased by $3 \%$.

The MR16 LED lamps exhibited more change in terms of lumen output and color. Their average lumen output decreased by almost $12 \%$ compared to the average of the six baseline tested lamps, and their power draw increased by $1 \%$. CCT decreased by $147 \mathrm{~K}$ (warmer), and CRI decreased by less than 0.5 points. $\Delta u^{\prime} v^{\prime}$ varied by 0.01354 (a 13-step Macadam ellipse or 13 just-noticeable differences).

\section{Reserved for results of $\mathbf{8 0 0 0}$ hour lamp testing}

\section{Reserved for results of 12,000 hour lamp testing}




\section{Contents}

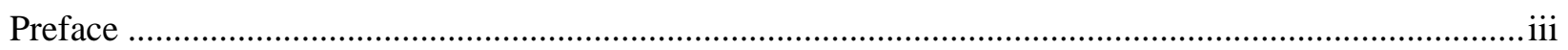

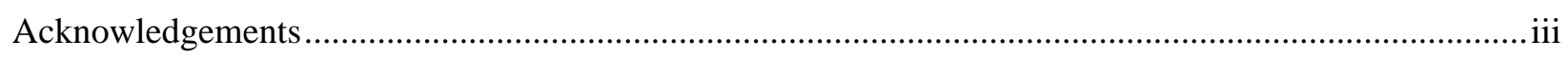

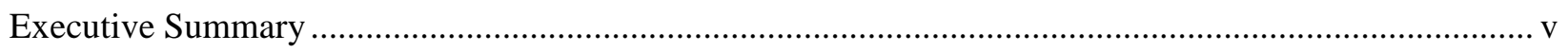

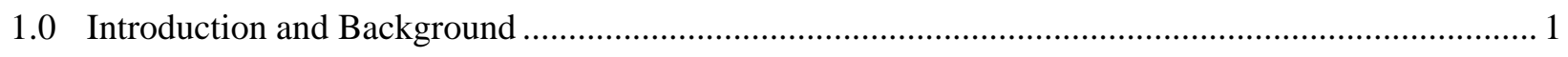

1.1 Interests and Concerns for LED Use in the Museum .......................................................... 2

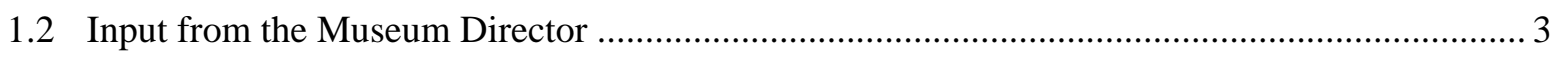

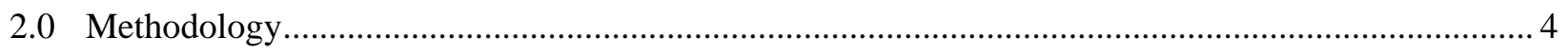

3.0 Demonstration Gallery Description, Lamps, Lamp Issues, and Measured Light Levels .................... 5

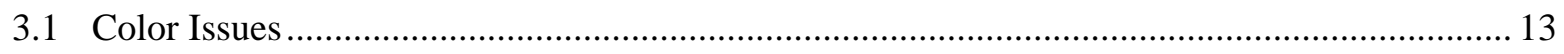

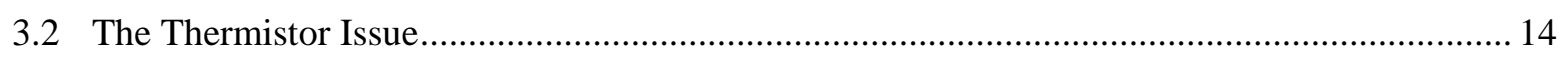

3.3 The Lighting Design, and the Lighting Designer's Reaction to LED Lamps ........................... 15

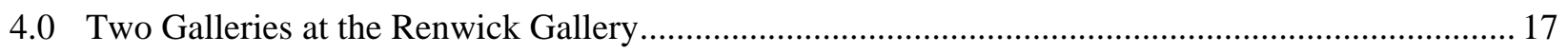

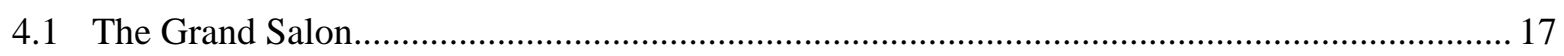

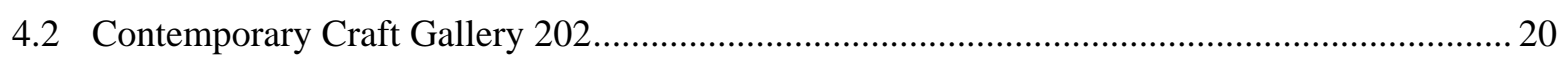

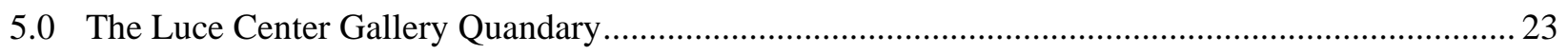

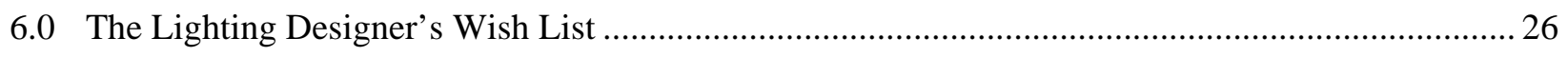

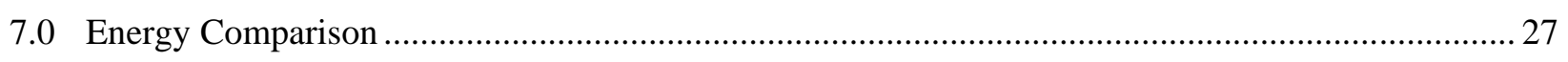

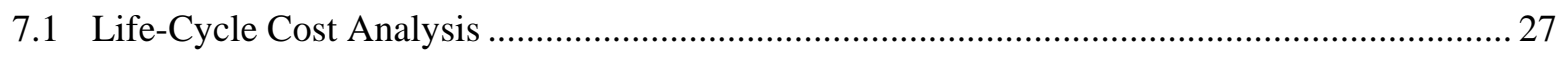

7.2 Payback Horizons and Economic Feasibility ................................................................... 28

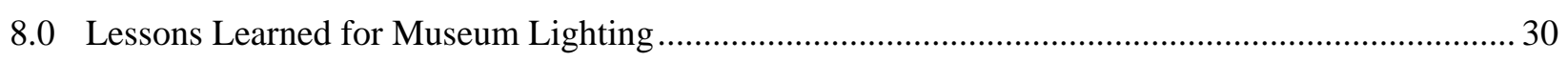

9.0 References for Museum Lighting and Artifact Conservation....................................................... 32

Appendix A : Smithsonian American Art Museum Early Modernism Gallery Input Data for

Life-Cycle Cost Analysis..................................................................................................... A.1

Appendix B : Summary Life-Cycle Cost Calculations ........................................................................

Appendix C : Comparative Analysis of Life-Cycle Cost.....................................................................1

\section{Figures}

Figure 1. The American Experience gallery at the Smithsonian American Art Museum, lighted with typical cylinder-shaped track heads.................................................................................... 2

Figure 2. Early test of LED replacement lamp in Rose Gallery. Photo courtesy of PNNL....................... 4

Figure 3. PAR30 display track head with three types of lenses (70, 55, and $55 \times 75^{\circ}$ ), and a

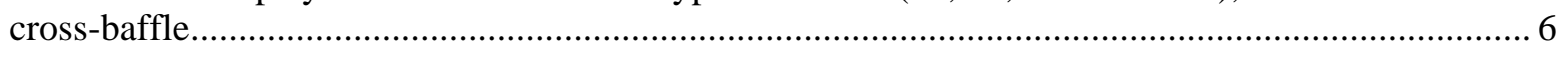

Figure 4. PAR30 wallwasher track head, shown with lens, light reduction screen, and optional

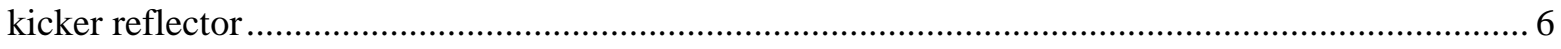

Figure 5. Early Modernism Gallery lighted with incandescent and halogen lighting ("before” condition). Photo by Scott Rosenfeld. 
Figure 6. One wall of the Early Modernism Gallery lighted with incandescent and halogen lamps before the LED replacement lamp trials. Photo by Scott Rosenfeld.

Figure 7. Early Modernism Gallery relighted entirely with LED replacement lamps. Photo courtesy of the Smithsonian American Art Museum.

Figure 8. Plot of lux values measured on one painting in the Early Modernism Gallery. The variation over time is due to the thermistor built into the Solais PAR38 lamp. There is a $25 \%$ decrease from the highest to lowest measured illuminances. (Note that the values on the horizontal axis are not equally spaced. There was little measured change in output between 11:30 a.m. and 4 p.m.).

Figure 9. Early Modernism Gallery photographed with LED display lighting layer only. Photo by Scott Rosenfeld.

Figure 10. Early Modernism Gallery with LED wallwash lighting layer only. Photo by Scott Rosenfeld.

Figure 11. The Early Modernism Gallery with LED replacement lamps. Composite of display lighting and wallwashing. Photo by Scott Rosenfeld.

Figure 12. Renwick Gallery Grand Salon with $35 \mathrm{ft} 0$ in. ceiling, lighted with halogen and incandescent track lighting. Photo courtesy of the Smithsonian American Art Museum.

Figure 13. MSI SSL 10/12/16W Par38 Spot lamp used in the Renwick Gallery Grand Salon and the Contemporary Craft Gallery 202

Figure 14. The Renwick Gallery Grand Salon with LED replacement lamps in approximately one-third of the display track lighting located near the simulated skylight. There are approximately six MSI 16W LED PAR38 $10^{\circ}$ NSP lamps among the lamps used to light the wall on the left, but only incandescent lamps are used on the end wall. Photo by Scott Rosenfeld.

Figure 15. Philips 17W EnduraLED lamp used in Renwick Contemporary Craft Gallery 202 .........

Figure 16. Gallery 202 of the Renwick Gallery, lighted with MSI PAR38 10 NSP LED replacement lamps. $22 \mathrm{ft} 0$ in. ceiling. Photo and lighting design by Scott Rosenfeld.

Figure 17. Gallery 202 with original incandescent lamping (left) and LED lamping (right). Photos and lighting design by Scott Rosenfeld.

Figure 18. The Luce Center Gallery of the Smithsonian American Art Museum with storage galleries flanking the three-story center atrium. Photo courtesy of Smithsonian American Art Museum.

Figure 19. Typical display aisle of Luce Center Gallery with $8 \mathrm{ft} 0$ in. ceiling. Photo by Scott Rosenfeld.

Figure 20. MR16 track heads with electronic transformers used in Luce Center. Photo by Scott Rosenfeld.

Figure 21. Flicker checker top. The top image shows it at rest, the bottom left image shows the top spinning under LED sources with very low modulation (i.e., minimal flicker); the bottom right image shows the top spinning under a source with very high modulation (i.e., pronounced flicker). Photos by PNNL

\section{Tables}

Table 1. Comparison of incandescent/halogen and LED lamps used in the Early Modernism Gallery 
Table 2. Early Modernism Gallery lamp information and power use, before and after the change to LED lamping

Table 3. Comparison of lamping and wattage before and after partial change to LED lamps in the Grand Salon.

Table 4. Halogen/Incandescent and LED Lamping in the Renwick Gallery, Gallery 202.

Table 5. Life-cycle cost input and comparative data for incumbent halogen/incandescent lamping in the Early Modernism Gallery. Analysis includes estimated labor costs for relamping.

Table 6. Comparative present value cost and energy of the LED lamps over 10-year analysis period, according to average electrical rate. Simple payback values are compared to the baseline halogen/incandescent lamping. Note that simple payback periods are shorter when energy prices are higher. 



\subsection{Introduction and Background}

The Smithsonian American Art Museum is an institution charged with storing, preserving, and displaying remarkable works produced by American artists over three centuries. Located in a Greek Revival building in Washington, DC that originally housed the US Patent Office, it is a destination for the American public, international visitors, and art students. Since 1972, the American Art Museum has also included the Renwick Gallery, which is the home for the Smithsonian Institution's craft and decorative arts program. Located near the White House in a Second Empire-style building, the Renwick features the best in two centuries of American clay, fiber, glass, metal, and wood arts. Visitors can enjoy traditional native and folk crafts, fine furniture, oil paintings, and whimsical contemporary glass sculpture.

In the fall of 2010, Pacific Northwest National Laboratory (PNNL) contacted Scott Rosenfeld, the Museum's lighting designer, to see if the Museum would be interested in participating in a GATEWAY demonstration project using light-emitting diode (LED) replacement lamps for exhibit lighting. At that time, the museum industry was concerned about increased damage potential from LEDs and other lighting sources that deliver a spectrum with significant spikes in certain wavelengths. The Museum agreed to participate, based on a review of the existing literature performed by Steven Weintraub of Art Preservation Services for the American Institute of Conservation, and subsequent testing of solid-state lighting (SSL) sources on light sensitive materials performed by Jim Druzik of the Getty Conservation Institute.

The gallery lighting system at the Smithsonian Art Museum has more than 7000 late 20th-century track luminaires, with four different kinds of track heads. These heads were originally designed to accommodate halogen PAR38 lamps, halogen PAR30 lamps, MR16 halogen lamps (the track head incorporates an electronic 12V transformer), and PAR36 incandescent and halogen lamps (the track head incorporates a dual-tap $5.5 \mathrm{~V}$ and $12 \mathrm{~V}$ magnetic transformer). All of the track heads were designed for maximum flexibility, accommodating lenses, theatrical filters, louvers, baffles, snoots, screens, and wallwasher reflectors that allow the PAR lamp light beam to be sculpted to create the ideal light distribution for the area or artwork. These accessories can also control glare and reduce illuminance to the maximum levels recommended for each individual work. Figure 1 shows a typical track head installation using halogen PAR30 lamps in one of the museum galleries. 


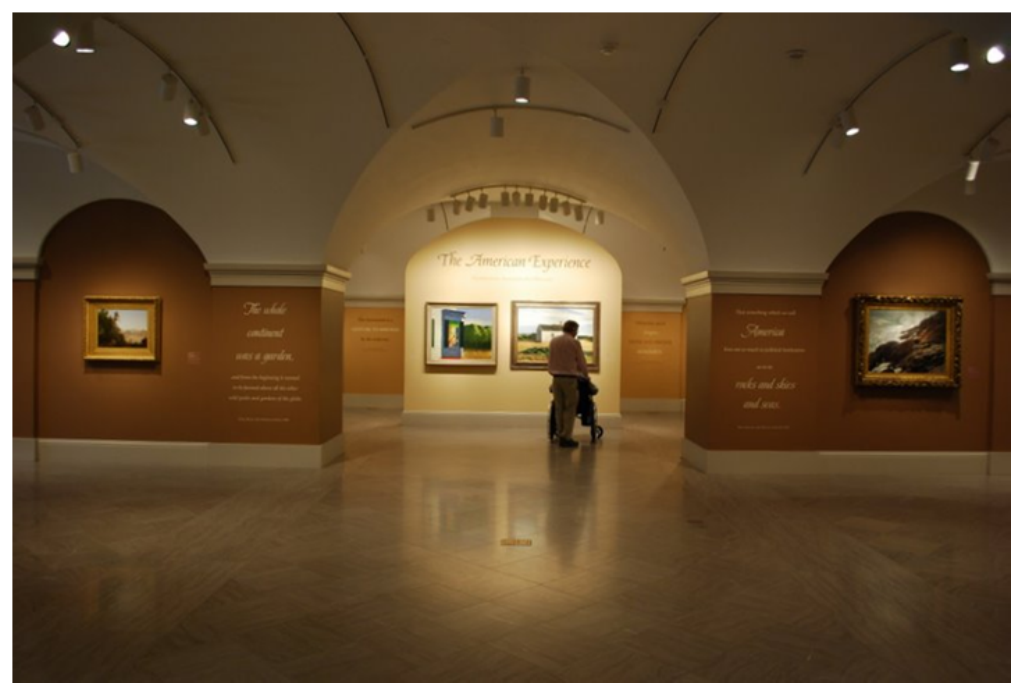

Figure 1. The American Experience gallery at the Smithsonian American Art Museum, lighted with typical cylinder-shaped track heads.

Lamp samples and performance data were collected for more than a year, with lamps first tested in the museum lighting workshop, then temporarily installed in one gallery for feedback from staff.

Ultimately, all traditional incandescent lamps in one gallery of modernist art at the American Art Museum were replaced, and lamps in two galleries of the Renwick Gallery were partially replaced.

This report describes the process and results of a demonstration of solid-state lighting technology in the Smithsonian American Art Museum, and communicates the successes and limitations of the technology as experienced by the lighting designer.

\subsection{Interests and Concerns for LED Use in the Museum}

Even before the GATEWAY demonstration project, the staff lighting designer's interest in LED lamps had been growing for several reasons:

- Energy savings: Electricity rates at the Smithsonian Institution museums in Washington, DC are relatively high, at an approximate melded (or "blended”) rate of $\$ 0.14$ per $\mathrm{kWh}$. The high number of halogen lamps in the galleries not only contributes to high energy bills and related environmental concerns, but also increases the need for air conditioning to maintain acceptable temperature and humidity conditions for valuable art. LED replacement lamps had the potential to reduce that energy use by $75 \%$ or more.

- Improved visual appearance: The spectral power distribution (SPD) of the LED lighting systems potentially offered new ways to improve the visual appearance and appreciation of certain types of art. While a higher correlated color temperature (CCT) lamp (i.e., LED) could be difficult to integrate without appearing stark or out of place in the gallery, even 2700K and 3000K LED lighting could improve three applications where the yellowness of the $2700 \mathrm{~K}$ incandescent sources is a hindrance:

- Wallwashing for landscape paintings, where blue skies never appear vivid under incandescent 
- Black and white photography, where existing incandescent lamps at the museum render the whites and grays as yellow

- Contemporary art, where the white walls of the gallery would look whiter under a higher kelvin source, or a 2700-3000K LED source with slightly more blue content than halogen delivers

- RP-30 considerations: As chair of the Illuminating Engineering Society of North America (IES) Museum Lighting Committee, the staff lighting designer was responsible for updating the Recommended Practice for Lighting of Museums (RP-30), and firsthand experience with LEDs in a museum setting would be helpful toward relating the realistic potential of this new lighting technology. LEDs are a new tool available for the lighting designer's toolbox.

The Museum's interest in LED lighting was tempered by uncertainty in the museum community about whether the LED spectrum could increase fading or photochemical damage to sensitive art. The GATEWAY demonstration offered a way to explore all of these issues, including contact with the Getty Conservation Institute, which was comparing the photodegradation from LEDs with traditional halogen light sources. (For more detail on the conservation issues, see the GATEWAY report for the J. Paul Getty Museum, http://apps1.eere.energy.gov/buildings/publications/pdfs/ssl/getty_museum_gateway_final.pdf.)

\subsection{Input from the Museum Director}

The project began with a discussion with the American Art Museum's Director, Elizabeth Broun, to explain the process of evaluating LED light sources, establish expectations about acceptable changes to the visual appearance of the gallery and individual artworks, and discuss the potential benefits and drawbacks of the new light sources and how they might be perceived by critics, curators, conservators, and the viewing public. Ms. Broun agreed to allow a trial demonstration in the Early Modernism Gallery (see Figure 2), which, if proven successful, would be expanded to additional galleries. She instructed the lighting designer to match the incandescent color of the existing lighting. She expressed a strong preference for the color rendering properties of incandescent lighting and was concerned that introducing a cooler light source might oversaturate the colors on the paintings. During the design process, the demonstration team found additional benefits of using an incandescent spectrum (2700-2850K) in that the new LEDs matched the rest of the galleries. (The lighting designer believes that, unless there is a compelling reason to the contrary, luminaires in all adjacent art galleries should have the same color temperature.)

Of course, paramount to this testing was ensuring that the LED lamps would cause no greater harm to the art than conventional halogen lamps, and that the LEDs would not negatively affect appreciation of the color, composition, and artist's intent. 


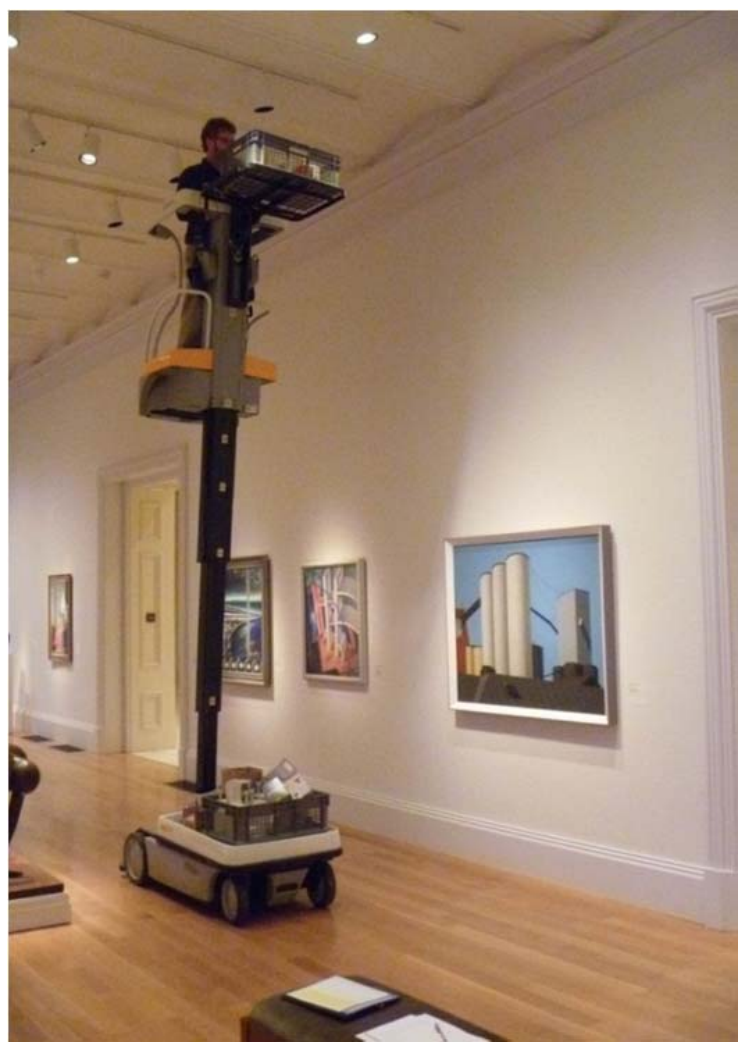

Figure 2. Early test of LED replacement lamp in Rose Gallery. Photo courtesy of PNNL.

\subsection{Methodology}

The museum and PNNL performed the following steps for this LED demonstration:

- LED replacement lamp products that fit the museum's existing track heads were researched.

Resources included detailed CALiPER ${ }^{1}$ reports on specific products. Samples of promising products were requested from manufacturers for mockup and visual evaluation. Procured lamps were first tested in their lighting laboratory spaces for light output, beam size and quality, and color characteristics by museum lighting staff. The best of these lamps were then mocked up in track lighting in the Early Modernism Gallery.

- Installed LED lamps were evaluated in one end of the Early Modernism Gallery for several weeks. Some lamps were deemed appropriate for the long-term installation, while others were found to be incompatible with existing track heads or their color was judged inappropriate. Ultimately, three beam spreads of one manufacturer's PAR30 replacement lamps were selected for the final installation, along with one manufacturer's 12V MR16 replacement lamps.

- Six of the LED PAR30 $10^{\circ}$ narrow spot (NSP) lamps, six of the PAR30 $40^{\circ}$ flood (FL) replacement lamps, and six of the 12V MR16 lamps were sent to a photometric laboratory for testing to document initial color, power, and lumen output performance. The lamp choices and numbers of track heads

\footnotetext{
${ }^{1}$ The DOE Commercially Available LED Product Evaluation and Reporting (CALiPER) program (http://www1.eere.energy.gov/buildings/ssl/about_caliper.html) supports testing of a wide array of SSL products available for general illumination. DOE allows its test results to be distributed in the public interest for non-commercial, educational purposes only.
} 
were documented before and after the final change. Lamps were installed in track luminaires and aimed by museum lighting staff. The lighting designer photographed the gallery before and after the lamp changes.

- Information was collected on hours of operation for the lighting system and the cost of power in the museum.

- Energy use was calculated and illuminances measured.

- The director of the American Art Museum, the curators, and docents were invited to share their reactions to the appearance and visibility of the art under the LED lamping.

- Upon a favorable reaction to the Early Modernism Gallery’s LED lamping, two galleries at the Renwick Museum were also tested and ultimately lamped with LED replacement lamps. The lighting designer followed a similar process to replace 12V MR16 halogen lamps in the Luce Center Gallery.

- A life-cycle cost study was performed to document the financial implications of the LED solution.

- After 4000 operation hours were logged, two lamps of each type were removed from the Early Modernism Gallery and shipped to a photometric laboratory for measurements to be compared to baseline measurements. This will also happen at 8000 hours and 12,000 hours of operation, and the results documented in updates to this report.

- Relative performance of the LED lighting systems in three galleries was documented in this GATEWAY report.

\subsection{Demonstration Gallery Description, Lamps, Lamp Issues, and Measured Light Levels}

The Smithsonian American Art Museum is investigating the use of LED lighting products to reduce energy costs for lighting and air conditioning, reduce carbon emissions, reduce maintenance costs through longer lamp life, and reduce, if possible, any photodegradation effects on its collection. The museum's lighting designer welcomed the challenge of viewing and evaluating a wide variety of LED replacement lamp types to see if he could retain the quality of lighting produced by the existing incandescent lighting system using more energy efficient technologies. In previous years, attempts to use fluorescent products for wall grazing had failed because it was difficult to control glare from the fluorescent luminaires and because they illuminated the top third of the wall more brightly than the bottom third. Metal halide luminaires were very costly and produced a harmful amount of ultraviolet emission that required extensive filtering to protect the works of art.

The Smithsonian American Art Museum's display lighting system was installed in 2006. The track heads, custom made by Zumtobel Lighting, were designed to accommodate a wide range of lamps and media. Between the flexibility of different halogen lamp beam angles and intensities, and the interchangeability of accessories, the lighting designer can create a specific appearance for each unique work of art. The track light used for focal lighting is illustrated in Figure 3, and the wallwasher in Figure 4. 


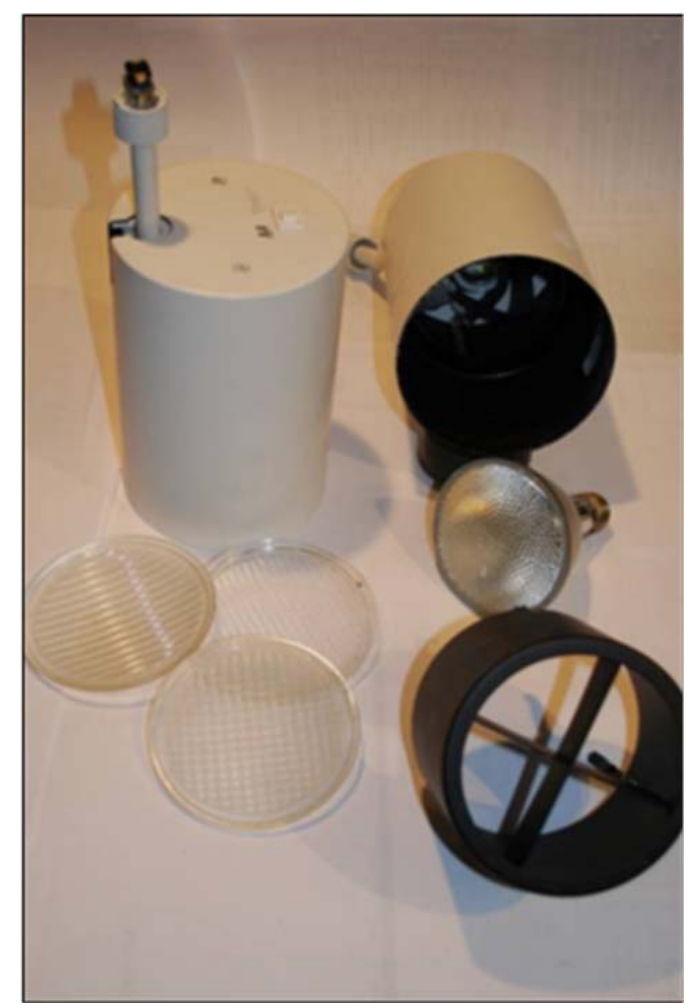

Figure 3. PAR30 display track head with three types of lenses (70, 55, and 55 x $75^{\circ}$ ), and a cross-baffle

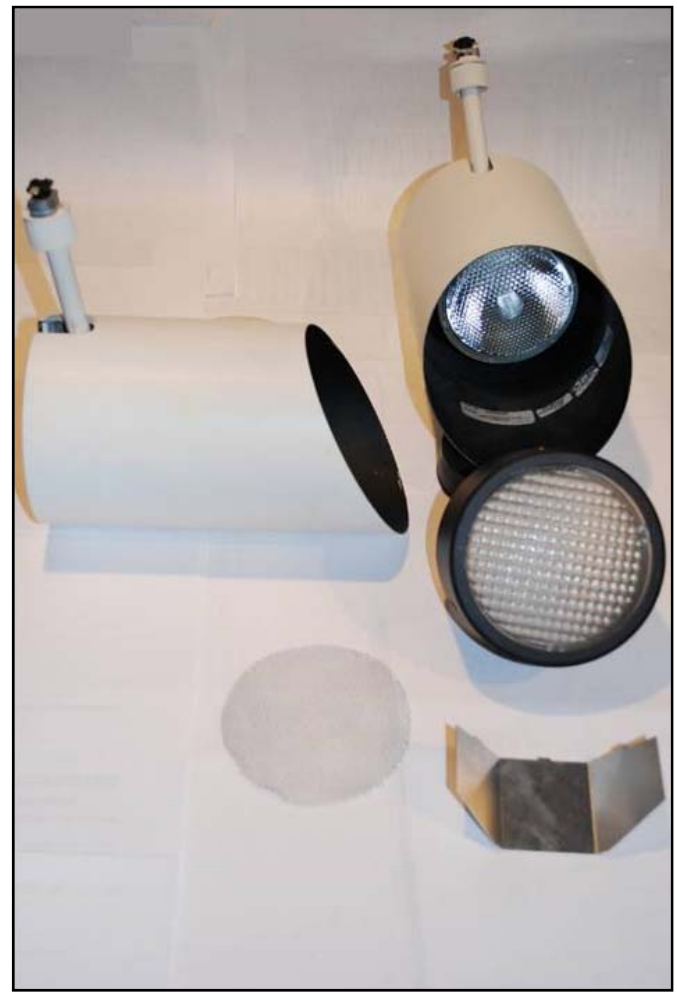

Figure 4. PAR30 wallwasher track head, shown with lens, light reduction screen, and optional kicker reflector 
New, dedicated LED track lighting was not considered for the Early Modernism Gallery because of the museum's extensive runs of existing track and large investment in existing track heads. The museum had conducted one brief experiment with a modular remote-phosphor LED product for wallwashing, but the optics of the sample track heads at the time were poor in terms of light distribution and glare control.

The wallwasher track head (shown in Figure 4) worked extremely well with the LED replacement lamp because the LED product's light distribution is very similar to that of the halogen PAR lamp it replaced when combined with spread and asymmetrical spread lenses. Asymmetrical spread lenses can be rotated in the fixture, spreading the light linearly and pushing it down the wall to where the art objects (and people) are. The cross baffle was especially important in the track heads used for focal lighting because of the increased direct glare potential for the light sources with exposed LEDs on the face of the lamp.

Not all of the halogen and incandescent lamps used in the track fixtures could be duplicated with LED lamps. The list of lamps and how their LED replacements performed is as follows:

- PAR38 lamp replacements barely fit in the PAR30 track heads, and were too big to fit when lenses and cross baffles were added for glare control. Although the Cree LRP38 LED replacement lamp worked well optically and provided excellent color, it was not used in the long-term test at the Early Modernism Gallery because of its size and because it was only available in one beam angle.

- Most PAR30 “long neck” LED replacement lamps were available in only one or two beam angles. Lamps from one manufacturer, Solais, were available in the desired $10^{\circ}, 25^{\circ}$, and $40^{\circ}$ angles and seemed to be very consistent in color and beam characteristics from lamp to lamp, and these were selected for long-term testing.

- Several 12V MR16 LED replacement lamps were tested, but only one LED MR16 lamp, by OptiLED, was ultimately selected for use. The halogen MR16 lamp is preferred for its small form factor, and its availability in angles ranging from $7^{\circ}$ (very narrow spot) up to $60^{\circ}$ (very wide flood). Few LED lamps with narrow spot or wide flood $\left(>30^{\circ}\right)$ distributions were available in late 2010/early 2011, and fewer still produced color that matched incandescent. Even fewer of those could operate on electronic transformers without producing a distracting $120 \mathrm{~Hz}$ flicker, although they usually did not flicker on magnetic transformers. (Interestingly, several MR16 LED lamps did not flicker noticeably until after a few days of operation.)

- The OptiLED “Accent Radar” MR16 lamp selected has very unusual optics, and interchangeable lenses in the aperture of the lamp to change the beam angle from $4^{\circ}$ to $80^{\circ}$. When unlensed, it produces a $4^{\circ}$ beam, which is comparable to the very narrow beams produced by 5.5V PAR36 lamps used in the museum's repertoire, although at much lower intensity. This OptiLED lamp became a favored lamp for small artworks. Because this unique lamp flickered on electronic transformers, the lighting designer adapted magnetic transformer track heads to accommodate it. (To date, this is the only LED product the lighting designer has seen with such a narrow beam.) According to the spinning top flicker checker (see Section 5), the OptiLED lamps still flicker some with the magnetic transformer, but not at a rate noticeable to any visitors so far. (The wallwashing and ambient light in the gallery essentially reduces the depth of the flicker waveform, making it less conspicuous.)

- $12 \mathrm{~V}$ and 5.5V PAR36 incandescent lamps are used for a very high degree of optical control, for wide washes $\left(55^{\circ}\right)$ and very narrow spots $\left(5^{\circ}\right.$ and $\left.9^{\circ}\right)$. At the time of the demonstration there were no LED replacement lamps that offered the required light output or specialized light distributions, so no PAR36 or AR111 LED replacements were used in the long-term testing galleries. 
Table 1 provides a summary of the selected lamps and their closest incandescent and/or halogen counterparts. 
Table 1. Comparison of incandescent/halogen and LED lamps used in the Early Modernism Gallery

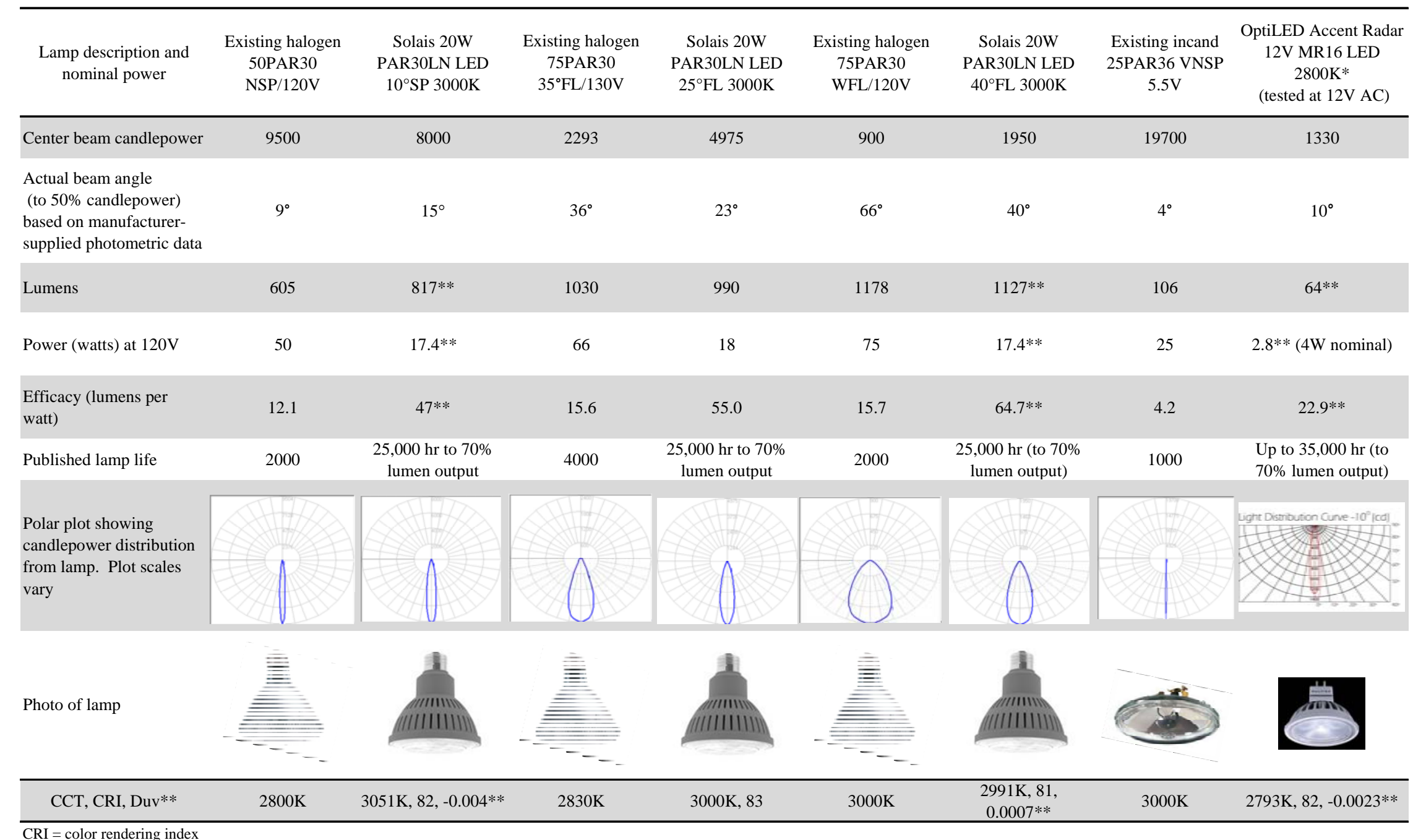

$\mathrm{CRI}=$ color rendering index

$\mathrm{CCT}=$ color correlated temperature

Duv $=$ difference above (+) or below (-) black body locus

* Based on $10^{\circ}$ distribution optics; $4^{\circ}$ distribution performance not available.

** Based on GATEWAY independent laboratory testing of new lamps where available; otherwise based on manufacturer's data. 


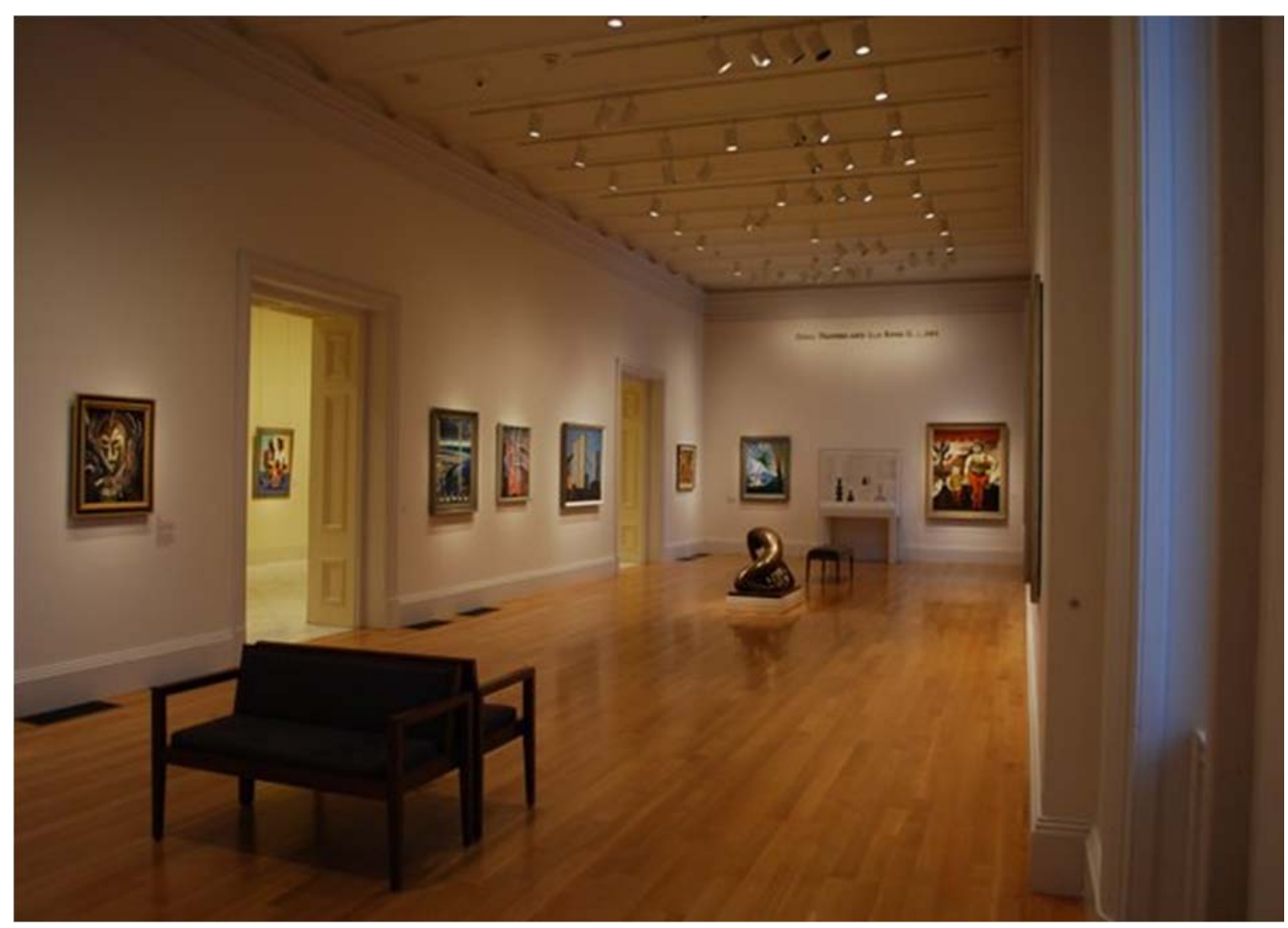

Figure 5. Early Modernism Gallery lighted with incandescent and halogen lighting ("before” condition). Photo by Scott Rosenfeld.

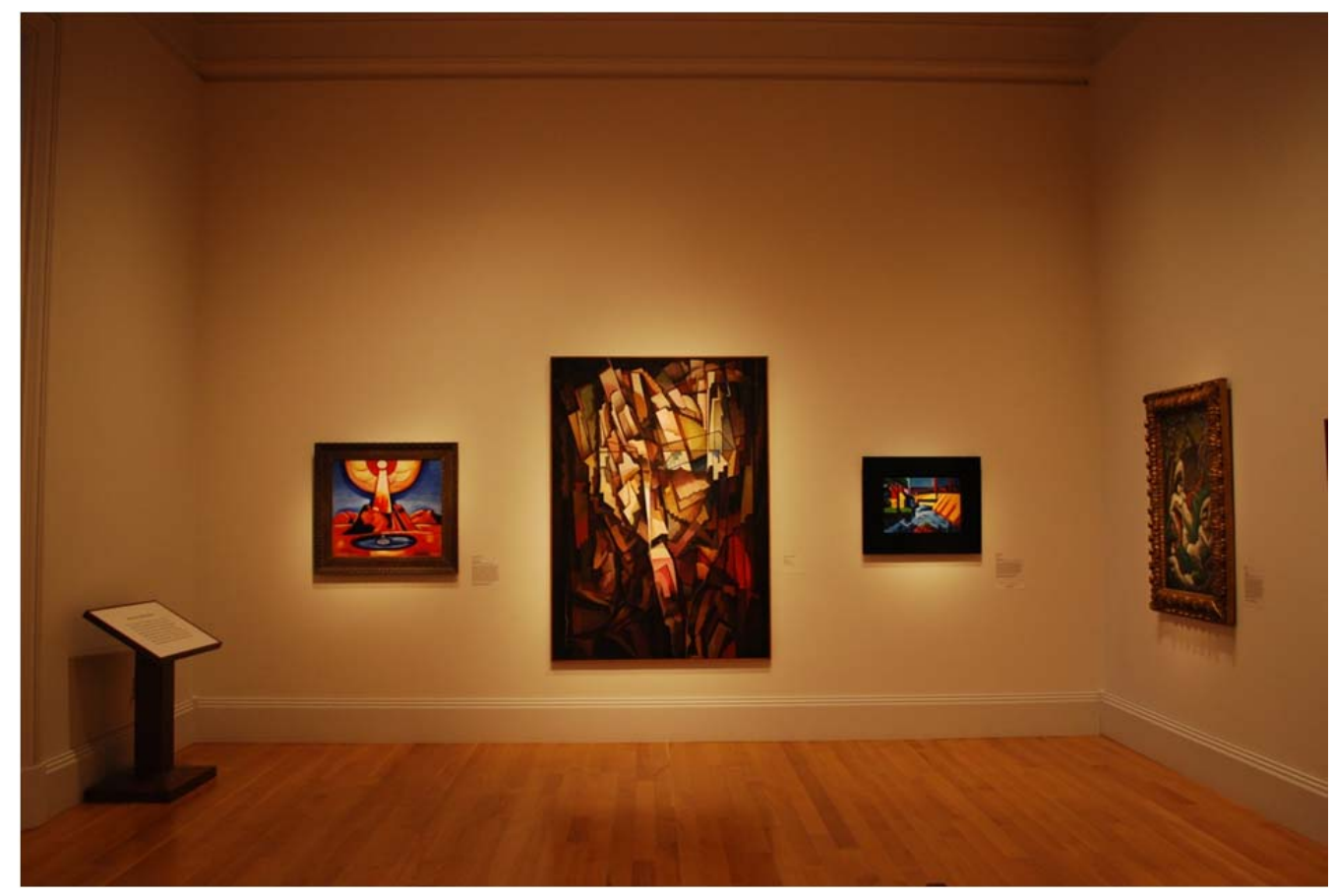

Figure 6. One wall of the Early Modernism Gallery lighted with incandescent and halogen lamps before the LED replacement lamp trials. Photo by Scott Rosenfeld.

The Early Modernism Gallery is $1200 \mathrm{ft}^{2}$ in area, with a $16 \mathrm{ft} 4$ in. ceiling. (See Figures 5 and 6.) Illuminance on the paintings is a compromise between low levels for conservation purposes and high 
levels for easy viewing. The museum director, curators, and lighting designer have agreed on a total target light level in this gallery of 150 to 250 lux (15 to 25 footcandles (fc)) vertical for oil paintings and 75 lux on very light sensitive works on paper, both limits including 50 to 60 lux (5 to $6 \mathrm{fc}$ ) vertical of wallwashing. No dimming is used in these galleries, and lights operate 11.5 hours per day, 365 days per year. Daylighting has been almost eliminated from the gallery, although a glow is visible through the carefully screened window openings. Ambient floor illuminance is 50 to 60 lux (5 to 6 fc).

The gallery's initial incandescent and/or halogen lamping is shown in Table 2, as is the LED lamping. Notice that there was no one-for-one replacement of lamp types, since there were no LED lamps that were exact duplicates of the original lamps. Even though the numbers and types of lamps used changed, they produced very similar visual effects and light levels. The total connected lighting load dropped from 3.9 $\mathrm{W} / \mathrm{ft}^{2}$ to $1.2 \mathrm{~W} / \mathrm{ft}^{2}$ as a consequence of redesign using LED replacement lamps. 
Table 2. Early Modernism Gallery lamp information and power use, before and after the change to LED lamping

\begin{tabular}{|c|c|c|c|c|c|c|c|c|c|}
\hline \multicolumn{10}{|c|}{$\begin{array}{l}\text { Gallery Height }=4978 \mathrm{~mm}(16 \mathrm{ft} 4 \mathrm{in} .) \\
\text { EXISTING INCANDESCENT LIGHTING }\end{array}$} \\
\hline $\begin{array}{c}\text { Incandescent Lamp } \\
\text { Type }\end{array}$ & Manufacturer & Quantity & Watts & $\begin{array}{l}\text { Total } \\
\text { Watts }\end{array}$ & $\begin{array}{l}\text { Lamp } \\
\text { Volt }\end{array}$ & Lens & $\begin{array}{l}\text { Lamp } \\
\text { Life }\end{array}$ & $\begin{array}{c}\text { Lamp } \\
\text { Cost }\end{array}$ & Purpose/ Notes \\
\hline 50PAR36/VNSP & GE & 26 & 50 & 1300 & 12 & none & 1000 & $\$ 5.50$ & VNSP to spotlight artwork \\
\hline 50PAR36/NSP & GE & 2 & 50 & 100 & 12 & none & 2000 & $\$ 5.50$ & NSP to spotlight artwork \\
\hline 50PAR36/WFL & GE & 3 & 50 & 150 & 12 & none & 2000 & $\$ 5.50$ & wide flood signage \\
\hline 25PAR36 & GE & 10 & 25 & 250 & 5.5 & none & 2000 & $\$ 8.00$ & $\begin{array}{l}\text { Pin spot to spotlight } \\
\text { artwork }\end{array}$ \\
\hline 50PAR30/NSP & PHILIPS & 6 & 50 & 300 & 120 & $55^{\circ}$ & 2000 & $\$ 5.50$ & Spotlighting artwork \\
\hline 75PAR30/WFL & GE & 7 & 75 & 525 & 120 & $55 \times 75^{\circ}$ & 2000 & $\$ 4.67$ & Floor lighting \\
\hline 75PAR30/35 & GE & 32 & 66 & 2112 & 130 & $70^{\circ}$ & 4000 & $\$ 4.67$ & $\begin{array}{l}\text { wall lighting (lamp is } 75 \\
\text { watts @ 130v) }\end{array}$ \\
\hline \multirow[t]{3}{*}{ TOTAL } & & 86 & & 4737 & & & & & \\
\hline & \multicolumn{3}{|c|}{ square footage of gallery } & 1200 & & 365.76 & \multicolumn{2}{|l|}{$m^{2}$} & \\
\hline & \multicolumn{3}{|c|}{ WATT/FT $^{2}$} & 3.9 & & 13.0 & \multicolumn{2}{|l|}{$w / m^{2}$} & \\
\hline
\end{tabular}

\section{ROSE GALLERY. ROOM N244 (CONTINUED)}

Gallery Height $=4978 \mathrm{~mm}(16 \mathrm{ft} 4 \mathrm{in}$.)

LED LIGHTING INSTALLED FOR GATEWAY DEMONSTRATION PROJECT

\begin{tabular}{|c|c|c|c|c|c|c|c|c|c|}
\hline LED Lamp type & Manufacture & Quantity & Watts & $\begin{array}{c}\text { Total } \\
\text { Watts }\end{array}$ & $\begin{array}{c}\text { Lamp } \\
\text { Volt }\end{array}$ & Lens & $\begin{array}{c}\text { Lamp } \\
\text { Life }\end{array}$ & $\begin{array}{c}\text { Lamp } \\
\text { Cost }\end{array}$ & Purpose \\
\hline LR30LN SPOT & SOLAIS & 25 & 18 & 450 & 120 & none & 25000 & $\$ 75$ & spotlight artwork \\
\hline $\begin{array}{c}\text { Accent Radar 3.5W } \\
\text { MR-16 }\end{array}$ & OPTILED & 12 & 3 & 36 & 12 & none & $\begin{array}{l}\text { up to } \\
35000\end{array}$ & $\$ 30$ & Pinspot artwork \\
\hline LR30LN FLOOD & SOLAIS & 6 & 18 & 108 & 120 & none & 25000 & $\$ 75$ & spotlight artwork \\
\hline LR30LN FLOOD & SOLAIS & 7 & 18 & 126 & 120 & $55 \times 75^{\circ}$ & 25000 & $\$ 75$ & Floor lighting \\
\hline LR30LN FLOOD & SOLAIS & 32 & 18 & 576 & 120 & $70^{\circ}$ & 25000 & $\$ 75$ & wall lighting \\
\hline \multirow[t]{3}{*}{ TOTAL } & & 82 & & 1296 & & & & & \\
\hline & \multicolumn{3}{|c|}{ square footage of gallery } & 1200 & & 365.76 & $m^{2}$ & & \\
\hline & \multicolumn{3}{|c|}{ WATT/FT ${ }^{2}$} & 1.1 & & 3.5 & $w / m^{2}$ & & \\
\hline
\end{tabular}




\subsection{Color Issues}

The color spectrum of LED lamps varies slightly from that of incandescent lighting. Unlike incandescent, LED lamps allow designers to select from a variety of SPDs with different color attributes. Even small spectral differences, such as those that occur when the correlated color temperature (CCT) of the lamp is changed from $2700 \mathrm{~K}$ to $3000 \mathrm{~K}$, slightly increase the proportion of short wavelength energy, making blue tones, such as painted blue skies, more vivid. In early LED gallery trials, the higher CCT lamps with their slight color rendering differences gave the impression that the painting colors were more richly saturated (i.e., more colorful), and this was initially embraced by the design staff. However, the curatorial staff along with the museum director felt that the light of the 3000K Solais PAR30 lamps rendered the paintings too colorful (overly saturated) and found the comparatively cool light distracting; they preferred 2700K LED lamps because the light from these lamps matched the early 20th Century light under which the early modernist work was created. Consequently, it was decided that amber theatrical filters (Rosco 3443) would be used to filter out some of the extra blue energy so that the LED light closely matched the halogen lighting used in adjacent galleries. Figure 7 shows a photograph of the final gallery installation, including the filtered LED lamping.

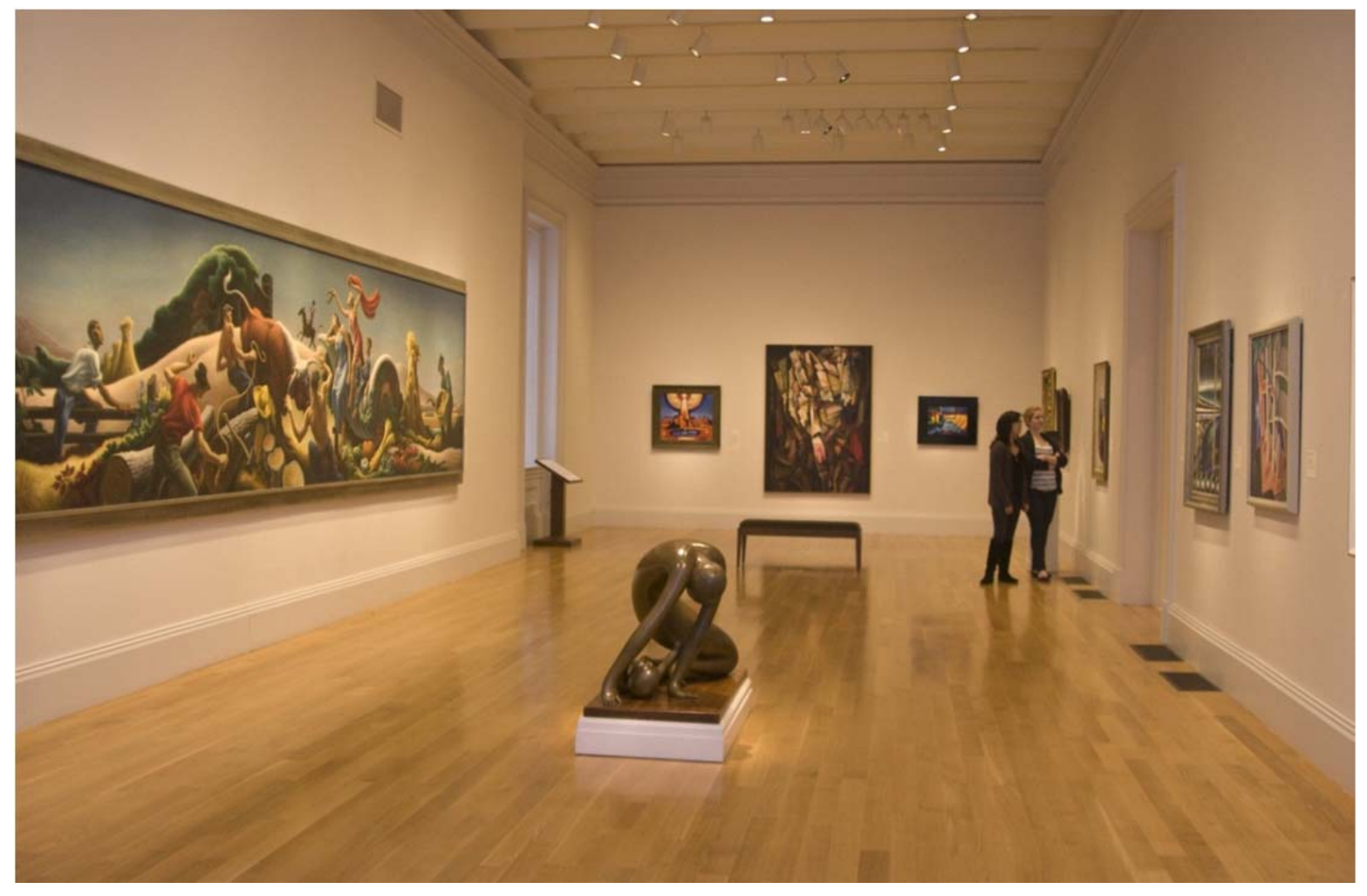

Figure 7. Early Modernism Gallery relighted entirely with LED replacement lamps. Photo courtesy of the Smithsonian American Art Museum.

The demonstration clearly showed very early on that color metrics such as CCT and color rendering index are a guideline for selecting sample lamps, but that no metrics can adequately communicate what the trained eye sees. There is no substitute for mockups in the actual space, lighting specific artwork, for making these color judgments. 


\subsection{The Thermistor Issue}

The Solais PAR30LN (longneck) LED lamps produced the best $10^{\circ}, 25^{\circ}$, and $40^{\circ}$ beams for the collection in terms of beam size, beam uniformity, beam edge, and color quality. However, the light output had to be modified with metal screens in order to limit the total display lighting on the paintings in the gallery to no more than 250 lux vertical. In the case of the track heads, which were used to produce a soft, low level of uniform background lighting ("wallwash”), one of two kinds of asymmetric glass lenses was clipped in front of the lamp. The glass or plastic media blocked normal air flow to the LED replacement lamps, which may have contributed to the lamp's rise in temperature. The lamp design contains a thermistor, which reduces the lamp wattage and light output by approximately $25 \%$ when it senses overheating, and the thermistor is not reset until the next time the lamp is switched on.

Consequently, the designer found that the output from these lamps could be expected to decrease over a period of 1 hour, and learned to apply final aiming and lens adjustments after the lamp had dropped in its output. Even at the lower output, the color and beam characteristics still made this a desirable lamp, and the thermistor behavior was acceptable in this gallery. Figure 8 plots the measured illuminance on one painting against time for this Solais LED PAR30 lamp.

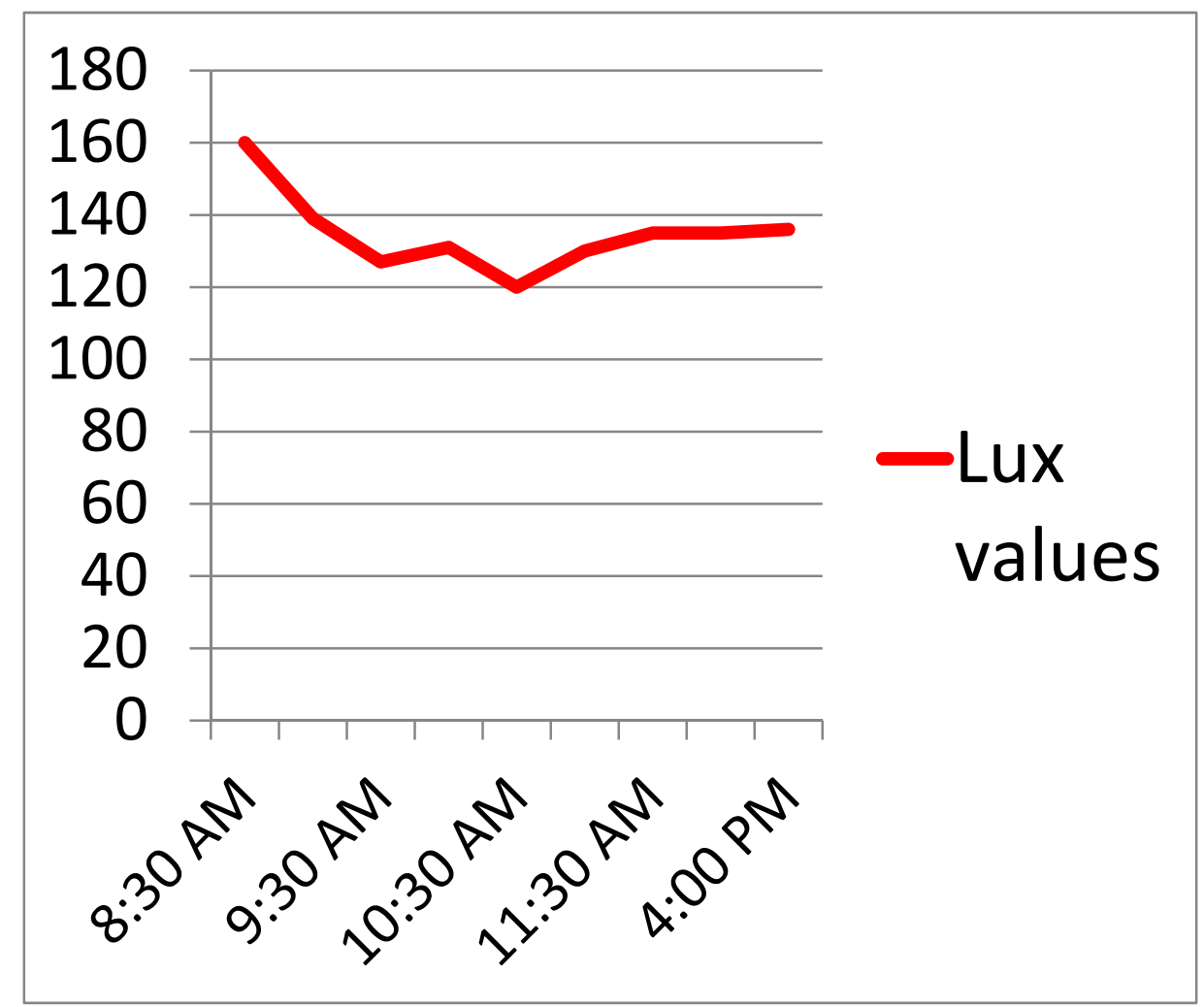

Figure 8. Plot of lux values measured on one painting in the Early Modernism Gallery. The variation over time is due to the thermistor built into the Solais PAR38 lamp. There is a $25 \%$ decrease from the highest to lowest measured illuminances. (Note that the values on the horizontal axis are not equally spaced. There was little measured change in output between 11:30 a.m. and 4 p.m.) 


\subsection{The Lighting Design, and the Lighting Designer's Reaction to LED Lamps}

The lighting designer's approach varies according to the characteristics of each individual piece of art. The type of artwork determines the choice of contrast between ambient lighting and a higher level of light focused on the piece itself. The contrast ratio in the Early Modernism gallery was approximately 3:1 in order to make the artworks slightly stand out against the background wall without dramatic halos surrounding the pieces. (It is worth noting that this designer's use of the illuminance meter is solely to meet conservation standards. Since each painting has different reflectance values, illuminances often vary widely in order to maintain a balanced look in the gallery. For example, the vertical illuminances on the paintings in this Early Modernism gallery range from 130 to 230 lux.)

The designer is also aware of the importance of delivering a pattern of light on the object that brings out important features, without introducing distracting highlights or shadows. Multiple luminaires equipped with lenses, louvers, baffles, and color filters are often used to create the ideal effect. Metal screens are cut to fit the track heads to reduce the light output without the color shift that dimming incandescent can cause, and multiple layers of screens may be used to reduce the illuminance to a level appropriate for conservation and viewing. While metal screens work well, they reduce the efficacy of the lighting system. LEDs offer the possibility that lamps can finally be dimmed individually without changing the color temperature.

Figure 9, Figure 10, and Figure 11 show one wall of the gallery using the display lighting layer only, the wallwashing layer only, and the final composite of the two.

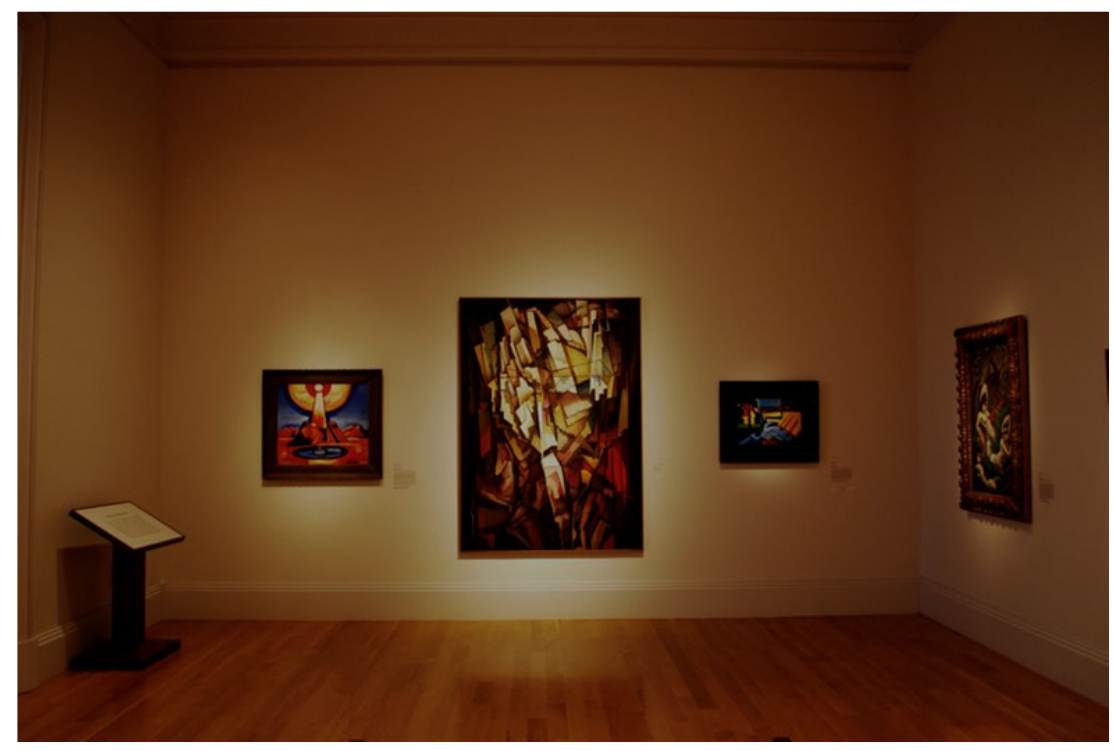

Figure 9. Early Modernism Gallery photographed with LED display lighting layer only. Photo by Scott Rosenfeld. 


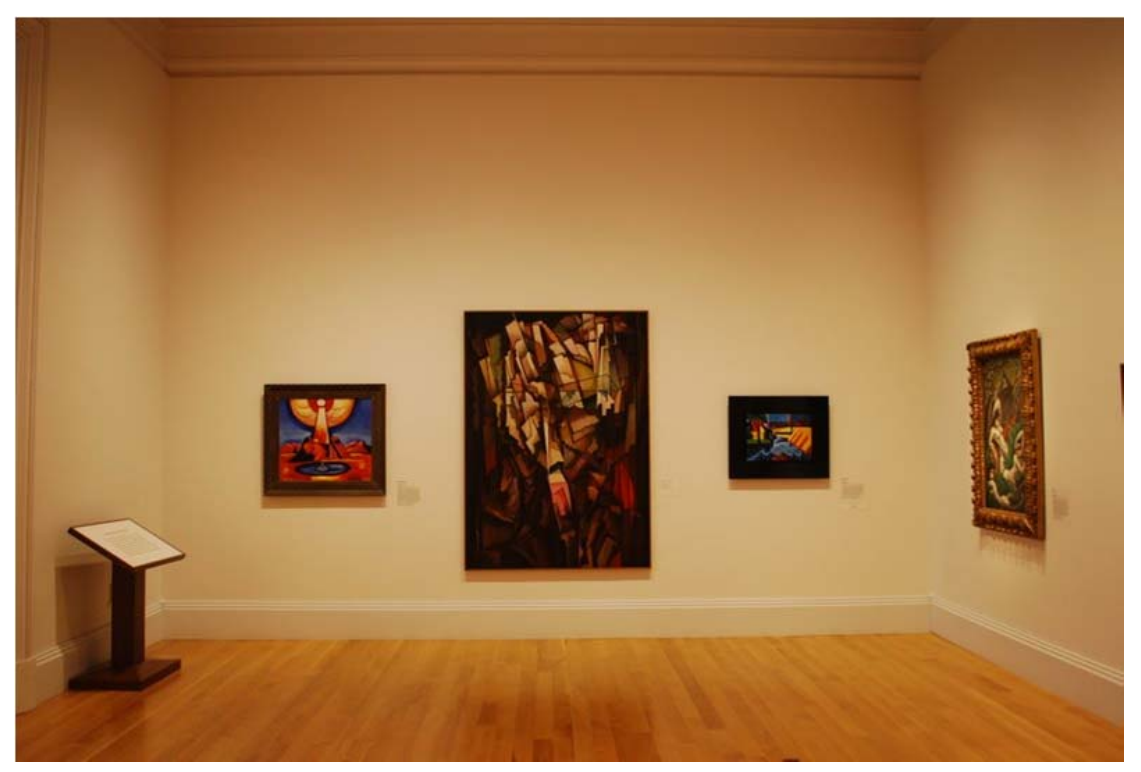

Figure 10. Early Modernism Gallery with LED wallwash lighting layer only. Photo by Scott Rosenfeld.

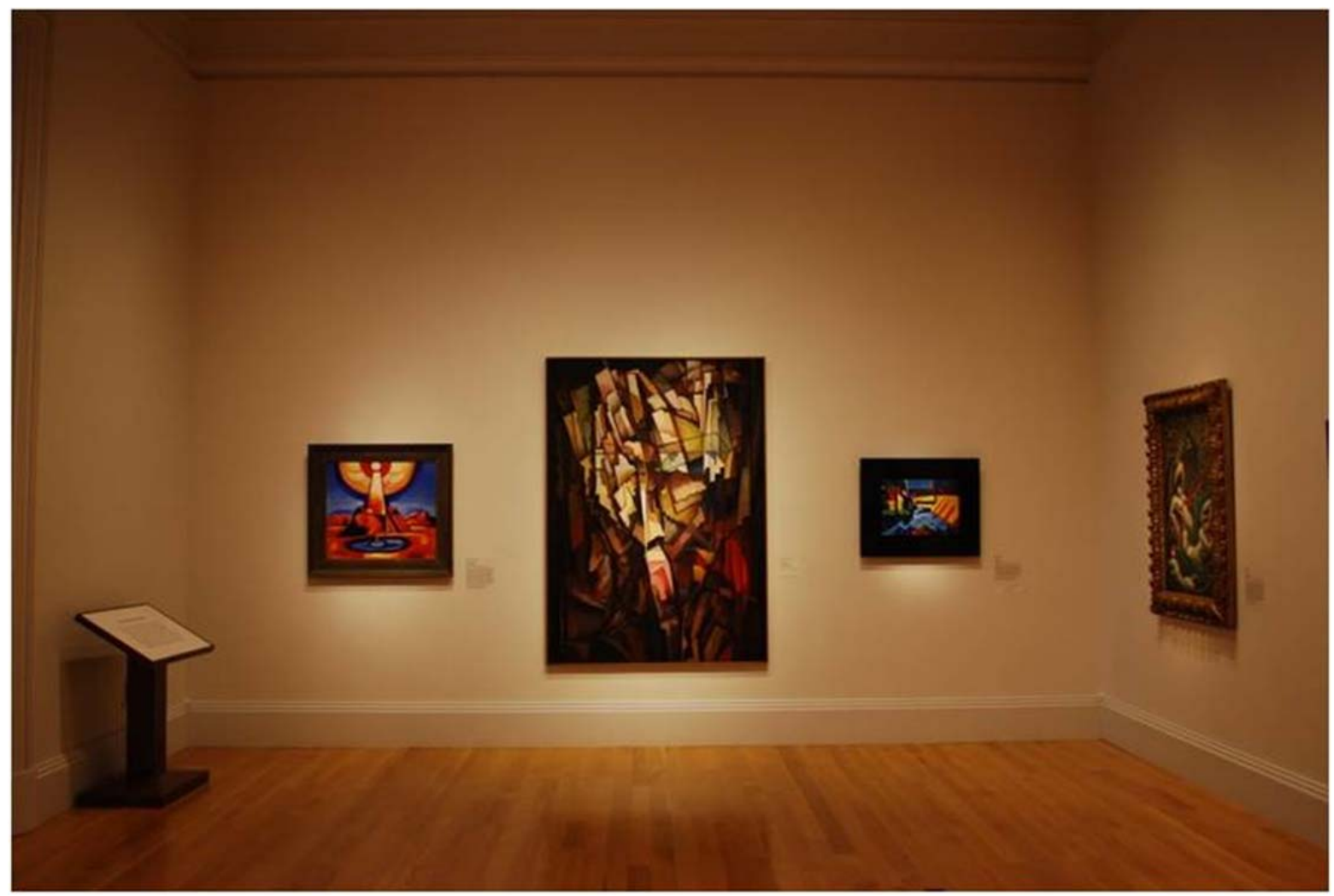

Figure 11. The Early Modernism Gallery with LED replacement lamps. Composite of display lighting and wallwashing. Photo by Scott Rosenfeld.

The demonstration in the Early Modernism Gallery showed that, although the lamps couldn't be replaced one-for-one, there were enough different types LED lamps available that the designer could 
achieve very satisfactory visual results in terms of both color and composition with LED lamps. This proves that energy efficiency does not necessarily require aesthetic sacrifice. In fact, LED lamps offered new opportunities for the designer to tailor the lamp spectrum.

\subsection{Two Galleries at the Renwick Gallery}

The Renwick Gallery is a branch museum of the Smithsonian American Art Museum dedicated to the collection and display of American Craft. Located across the street from the White House, the museum is housed in a building designed by James Renwick in 1859 as the first art museum in Washington, DC. Two galleries in the Renwick were chosen for LED demonstrations: the Grand Salon (with $35 \mathrm{ft} 0 \mathrm{in}$. ceilings) and Gallery 202 (with a $22 \mathrm{ft} 0$ in. ceiling).

\subsection{The Grand Salon}

Modeled after the Louvre's Tuileries galleries, the Grand Salon currently exhibits a collection of 19th and 20th century paintings from the Smithsonian American Art Museum. The Grand Salon exhibits paintings in multiple heights on the wall, as shown in Figure 12. The display track lighting is located next to the simulated skylight in the ceiling, and the throw distances to the objects can be $20 \mathrm{ft}$ or more. Consequently, the gallery generally uses high-wattage, narrow-distribution, high-intensity incandescent and halogen lamps, including 25W 6V PAR46 VNSP lamps with a center beam candlepower (CBCP) of 55,000 candelas (cd), 120W PAR38 $9^{\circ}$ NSP lamps with a CBCP of 18,000 cd, and 250W PAR38 $30^{\circ} \mathrm{FL}$ lamps (9000 CBCP, 3600 lumens) for wallwashing. Because LED replacement lamps are still evolving, they cannot yet deliver high-intensity spots or high-lumen packages for this kind of application. However, the designer was still able to substitute one-third of the lamps in the room with LEDs.

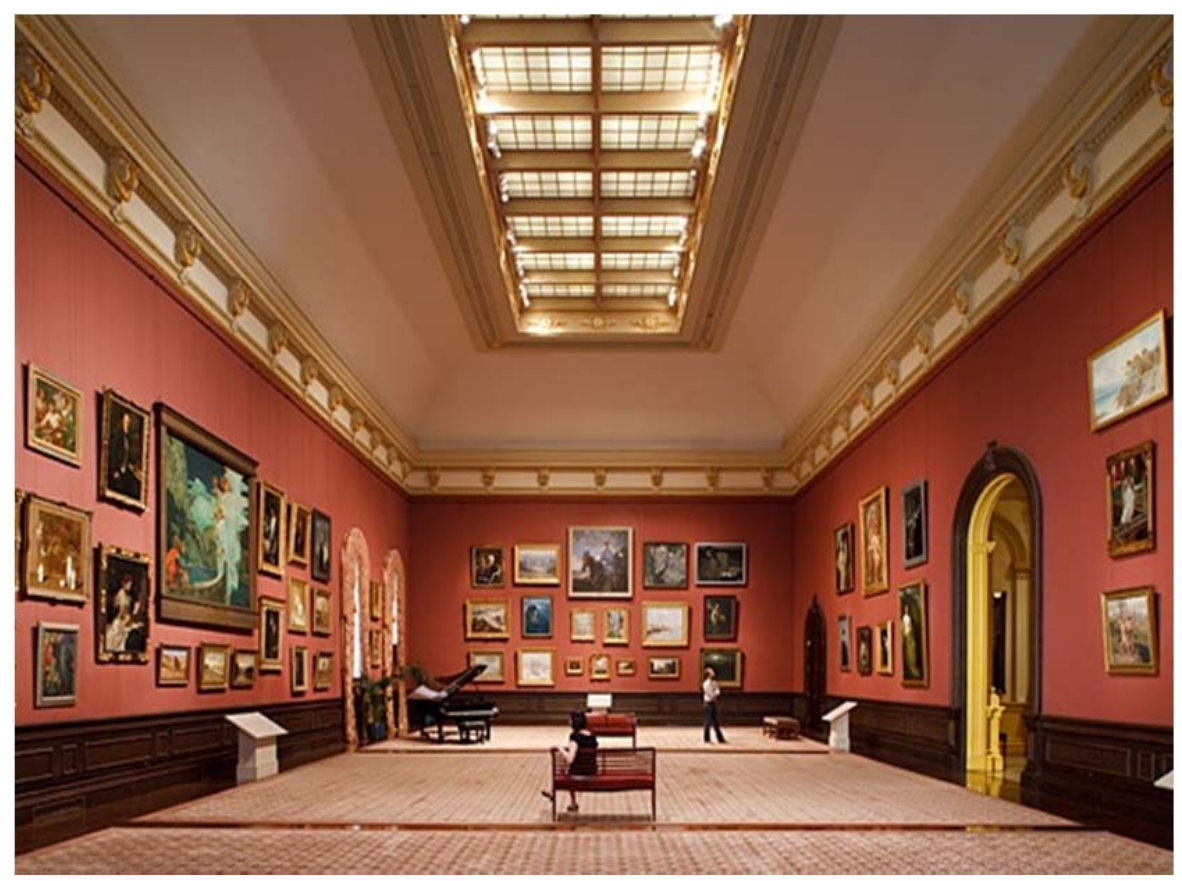

Figure 12. Renwick Gallery Grand Salon with $35 \mathrm{ft} 0$ in. ceiling, lighted with halogen and incandescent track lighting. Photo courtesy of the Smithsonian American Art Museum. 
Long throw distances called for narrow, intense beams of light for the specific art objects. The PAR38 LED replacement lamps from MSI delivered a $10^{\circ}$ beam that worked very well as an accent light for some works, allowing the designer to eliminate all 120W PAR38 SP10 ${ }^{\circ}$ halogen lamps, most 50W PAR36 VNSP6 ${ }^{\circ}$ halogen lamps, and several 250W PAR38 SP10 ${ }^{\circ}$ and 25W 5.5V PAR46 pinspot lamps. The MSI lamps, shown in Figure 13, have an adjustable ring that changes the wattage and light output from 10W (13,250 cd, 550 lumens) to $12 \mathrm{~W}$ (15,250 cd, 650 lumens) to $16 \mathrm{~W}$ (18,000 cd, 800 lumen) according to the manufacturer. This feature allowed the illuminance on the objects to be reduced to conservation levels and saved energy because the designer could reduce light output to the lowest level needed. The visual result of the partial change to LED lamps can be seen in Figure 14, and it resulted in an estimated reduction of 2054W in the Grand Salon, with a corresponding annual lighting energy savings of $\$ 1,294$, assuming 4500 annual operating hours at $\$ 0.14 / \mathrm{kWh}$. There has been no effort to publicize this partial lamp change in the Grand Salon, but it is significant that the changes seem to have gone unnoticed by the public so far. That may mean that the LED lamps blend well with the existing halogen sources still in use.

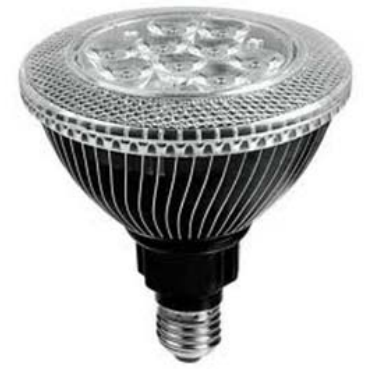

Figure 13. MSI SSL 10/12/16W Par38 Spot lamp used in the Renwick Gallery Grand Salon and the Contemporary Craft Gallery 202 
Table 3. Comparison of lamping and wattage before and after partial change to LED lamps in the Grand Salon.

Renwick Grand Salon - Partial replacement of incandescent lamps with LED lamps

Gallery Height $=35 \mathrm{ft}$

EXISTING INCANDESCENT LIGHTING THAT COULD BE REPLACED BY LED LAMPS

\begin{tabular}{|c|c|c|c|c|c|c|c|c|c|}
\hline Incandescent Lamp Type & Manufacturer & Quantity & Watts & $\begin{array}{l}\text { Total } \\
\text { Watts }\end{array}$ & Volt & Lens & $\begin{array}{c}\text { Lamp } \\
\text { Life }\end{array}$ & $\begin{array}{c}\text { Lamp } \\
\text { Cost }\end{array}$ & Purpose \\
\hline 120/PAR38/NARROW SPOT & SYLVANIA & 12 & 120 & 1440 & 120 & none & 2000 & $\$ 5.50$ & $\begin{array}{l}\text { NSP to spotlight } \\
\text { artwork }\end{array}$ \\
\hline 25watt/PAR46/5.5 volt pinspot & GE & 4 & 25 & 100 & 5.5 & none & 2000 & $\$ 23.00$ & $\begin{array}{c}\text { VNSP to spotlight } \\
\text { artwork }\end{array}$ \\
\hline 250watt/ PAR38 SPOT & GE & 3 & 250 & 750 & 120 & none & 2000 & $\$ 20.00$ & $\begin{array}{l}\text { SP to spotlight } \\
\text { artwork }\end{array}$ \\
\hline 50watt/PAR36/VNSP & PHILIPS & 2 & 50 & 100 & 12 & none & 2000 & $\$ 5.50$ & $\begin{array}{l}\text { VNSP to spotlight } \\
\text { artwork }\end{array}$ \\
\hline TOTAL & & 21 & & 2390 & & & & & \\
\hline
\end{tabular}

LED LIGHTING INSTALLED TO REPLACE SOME INCANDESCENT LIGHTING FOR GATEWAY DEMONSTRATION PROJECT

\begin{tabular}{|c|c|c|c|c|c|c|c|c|c|}
\hline LED Lamp type & Manufacturer & Quantity & Watts & $\begin{array}{c}\text { Total } \\
\text { Watts }\end{array}$ & Volt & Lens & $\begin{array}{c}\text { Lamp } \\
\text { Life }\end{array}$ & $\begin{array}{c}\text { Lamp } \\
\text { Cost }\end{array}$ & $\begin{array}{c}\text { Purpose } \\
\text { MSI PAR38 10/12/16 watt } 10^{\circ} \text { Spot }\end{array}$ \\
\hline TOTAL & MSI & 21 & 16 & 336 & 120 & none & 50000 & $\$ 75.00$ & Spotlight artwork \\
\hline
\end{tabular}




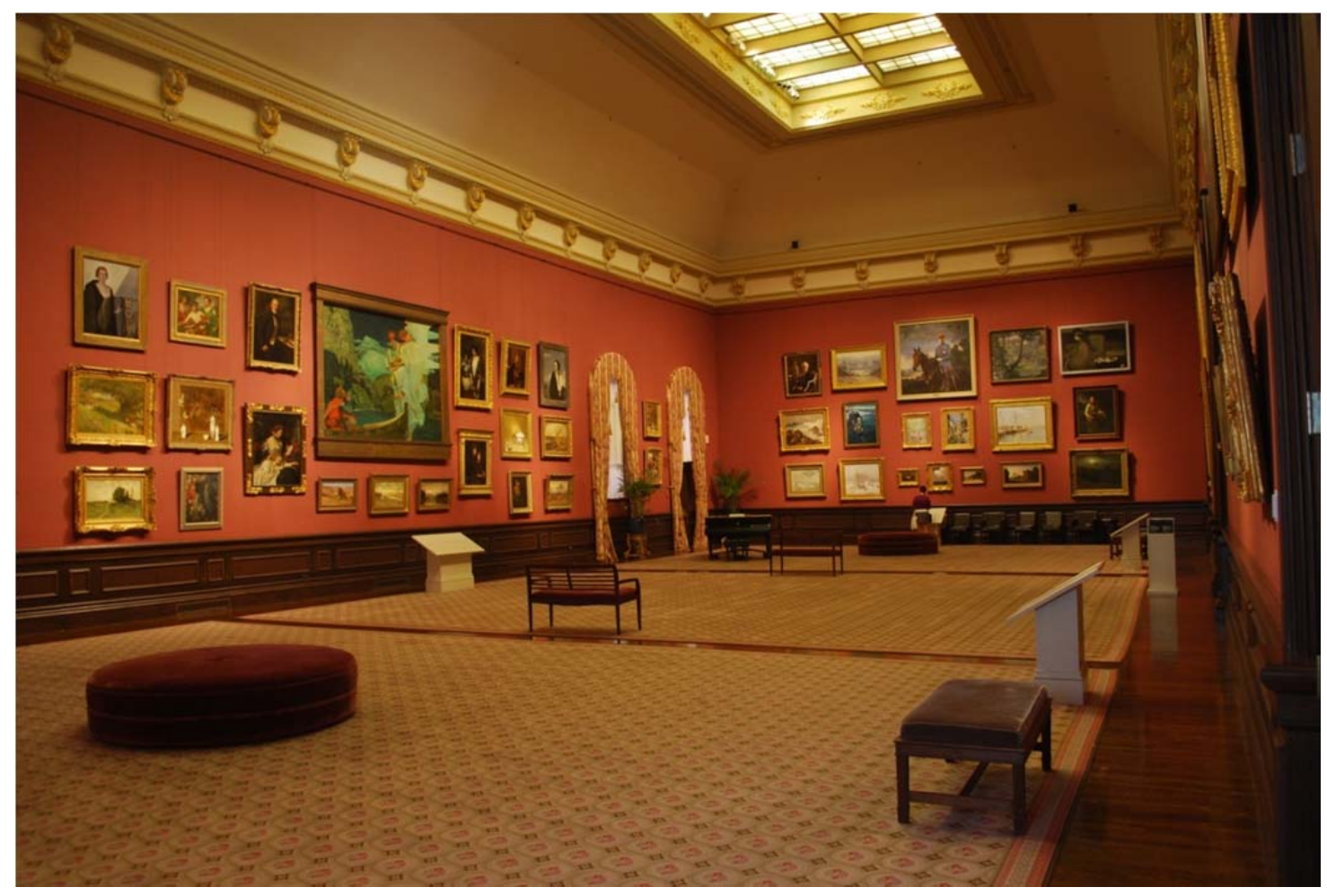

Figure 14. The Renwick Gallery Grand Salon with LED replacement lamps in approximately one-third of the display track lighting located near the simulated skylight. There are approximately six MSI 16W LED PAR38 $10^{\circ}$ NSP lamps among the lamps used to light the wall on the left, but only incandescent lamps are used on the end wall. Photo by Scott Rosenfeld.

\subsection{Contemporary Craft Gallery 202}

The Renwick is a comparatively small museum and rotates its collection frequently. The lighting needs to be flexible to accommodate a wide variety of materials. The featured object when LEDs were first installed was Beth Lipman's massive glass installation, Bancetje (a 20-foot-long oak banquet table with 400 clear blown glass objects) (Figure 16 and Figure 17). To illuminate Bancetje with halogen lamps (Figure 17) required installing lamps to one lighting circuit's maximum limit (16 amps) to achieve the degree of sparkle desired by the artist and the museum staff. (The museum lighting designer reports this is the only artwork in his 20-year career that required this high a power density to light.) The gallery's total connected load was 3590W.

Once again, finding LED lamps for this room required a significant amount of trial and error. As before, no single manufacturer offered all the light distributions and lumen packages needed for the variety of artwork, and not all lamps in a product line had the same color characteristics. However, the lighting designer was able to achieve the needed illuminances by incorporating twelve MSI PAR38 $10^{\circ}$ NSP LED lamps, three Philips 17W PAR38 2700K $22^{\circ}$ NFL LED lamps (Figure 15), and thirteen of the OptiLED 3.5W Accent Radar MR16 lamps into the lighting system, while using less than 1.6 amps on the circuit that had previously been fully loaded. The total connected load was reduced by $91 \%$, from $3590 \mathrm{~W}$ to $282 \mathrm{~W}$ and from $4.7 \mathrm{~W} / \mathrm{ft}^{2}$ to $0.4 \mathrm{~W} / \mathrm{ft}^{2}$. See Table 4 . Although the exhibit has changed twice since then, the designer reports that these lamps have performed just as well for subsequent exhibits. 


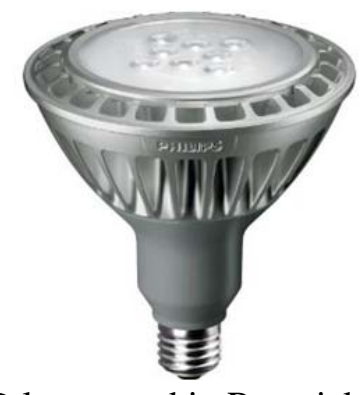

Figure 15. Philips 17W EnduraLED lamp used in Renwick Contemporary Craft Gallery 202

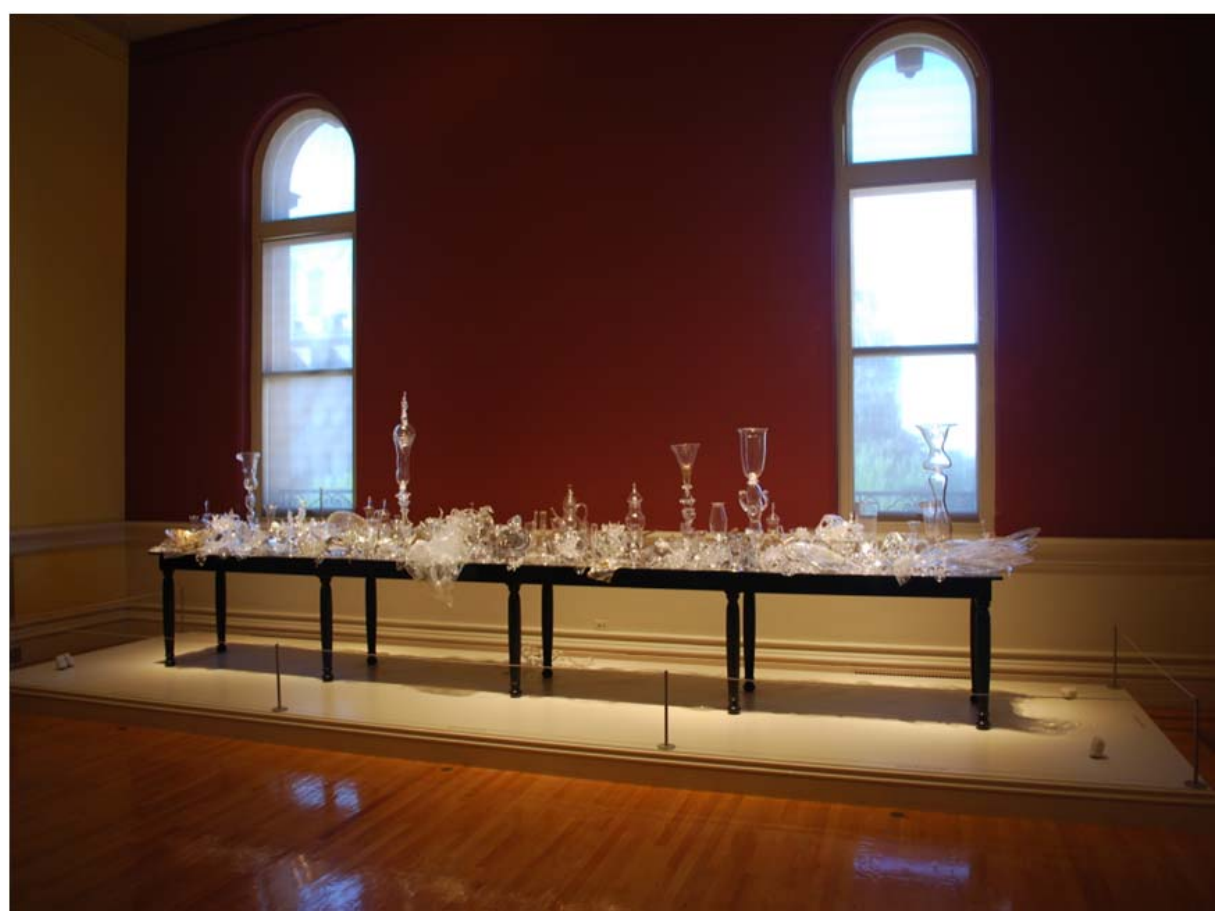

Figure 16. Gallery 202 of the Renwick Gallery, lighted with MSI PAR38 $10^{\circ}$ NSP LED replacement lamps. $22 \mathrm{ft} 0$ in. ceiling. Photo and lighting design by Scott Rosenfeld.
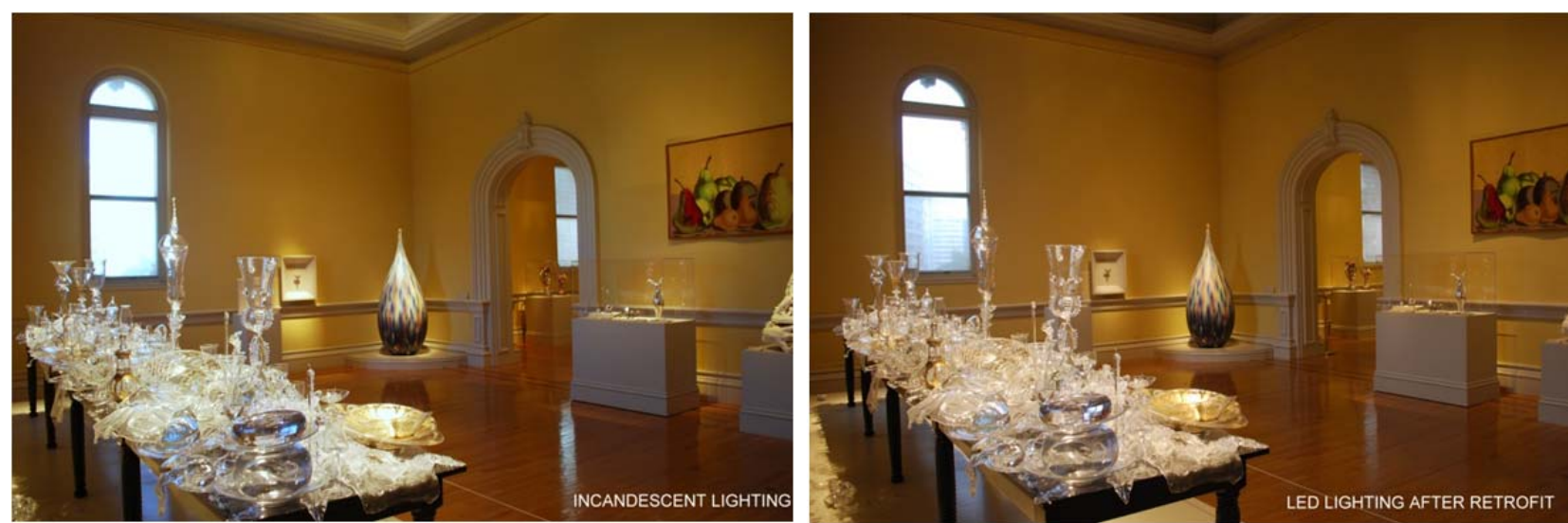

Figure 17. Gallery 202 with original incandescent lamping (left) and LED lamping (right). Photos and lighting design by Scott Rosenfeld. 
Table 4. Halogen/Incandescent and LED Lamping in the Renwick Gallery, Gallery 202

\section{Renwick Gallery 202}

Gallery Height $=6706 \mathrm{~mm}(22 \mathrm{ft} 0$ in. $)$

EXISTING HALOGEN LIGHTING

\begin{tabular}{|c|c|c|c|c|c|c|c|c|c|}
\hline Incandescent Lamp Type & Manufacturer & Quantity & Watts & $\begin{array}{c}\text { Total } \\
\text { Watts }\end{array}$ & Volt & Lens & $\begin{array}{c}\text { Lamp } \\
\text { Life }\end{array}$ & $\begin{array}{c}\text { Lamp } \\
\text { Cost }\end{array}$ & $\begin{array}{c}\text { Purpose } \\
\text { 50PAR36/VNSP }\end{array}$ \\
\hline GE & 19 & 50 & 950 & 12 & none & 2000 & $\begin{array}{c}\$ 5.50 \\
\text { VNSP to spotlight } \\
\text { artwork }\end{array}$ \\
\hline 50/AR111 4 degree & SYLVANIA & 9 & 50 & 450 & 12 & none & 2000 & $\$ 5.50$ & $\begin{array}{c}\text { NSP to spotlight } \\
\text { artwork }\end{array}$ \\
\hline 25PAR36 & GE & 12 & 25 & 300 & 5.5 & none & 2000 & $\$ 8$ & $\begin{array}{c}\text { Pin spot to spotlight } \\
\text { artwork }\end{array}$ \\
\hline 90PAR38/FL & SYLVANIA & 5 & 90 & 450 & 120 & none & 2000 & $\$ 6$ & Floodlighting for walls \\
\hline 120PAR38/NSP & GE & 12 & 120 & 1440 & 120 & 55 & 2000 & $\$ 6$ & Spotlight for artwork \\
\hline TOTAL & \multicolumn{2}{|c|}{ square footage of gallery } & $\mathbf{7 6 8}$ & & $\mathbf{2 3 4 . 1}$ & $\mathbf{m}^{2}$ & & \\
\hline
\end{tabular}

LED LIGHTING INSTALLED FOR GATEWAY DEMONSTRATION PROJECT

\begin{tabular}{|c|c|c|c|c|c|c|c|c|c|}
\hline LED Lamp type & Manufacturer & Quantity & Watts & $\begin{array}{l}\text { Total } \\
\text { Watts }\end{array}$ & Volt & Lens & $\begin{array}{l}\text { Lamp } \\
\text { Life }\end{array}$ & $\begin{array}{c}\text { Lamp } \\
\text { Cost }\end{array}$ & Purpose \\
\hline $\begin{array}{l}\text { MSI PAR38 10/12/16 W 10 } \\
\text { Spot }\end{array}$ & MSI & 25 & 16 & 400 & 120 & none & 50000 & $\$ 75$ & Spotlight artwork \\
\hline $\begin{array}{l}\text { Philips PAR38 } 17 \mathrm{~W} 22^{\circ} \mathrm{NFL} \\
\text { 2700K } 120 \mathrm{~V}\end{array}$ & PHILIPS & 15 & 17 & 255 & 120 & LOL & 50000 & $\$ 105$ & $\begin{array}{l}\text { Floodlight artwork and } \\
\text { walls }\end{array}$ \\
\hline $\begin{array}{l}\text { OptiLED Accent Radar 3.5W } \\
\text { MR-16 }\end{array}$ & OPTILED & 25 & 3 & 75 & 12 & none & $\begin{array}{l}\text { Up to } \\
35000\end{array}$ & $\$ 30$ & Pinspot artwork \\
\hline \multirow[t]{3}{*}{ TOTAL } & & 65 & & 730 & & & & & \\
\hline & \multicolumn{2}{|c|}{ square footage of gallery } & \multicolumn{2}{|r|}{768} & & 234.1 & $m^{2}$ & & \\
\hline & \multicolumn{2}{|c|}{ WATT/FT $^{2}$} & & 1.0 & & 3.1 & $w / m^{2}$ & & \\
\hline
\end{tabular}




\subsection{The Luce Center Gallery Quandary}

The Luce Foundation Center for American Art (Figure 18) is high-density visible art storage featuring 3500 paintings, sculptures, miniatures, and folk art pieces from the collection of the Smithsonian Art Museum. The collection is stored in 64 cases where the art is fully accessible to the public and scholars. The Luce Center is housed in one of the grand rooms of the Old U.S. Patent Office, which was built to store scale models for patent applications. Ceilings are only $8 \mathrm{ft}$ high (Figure 19).

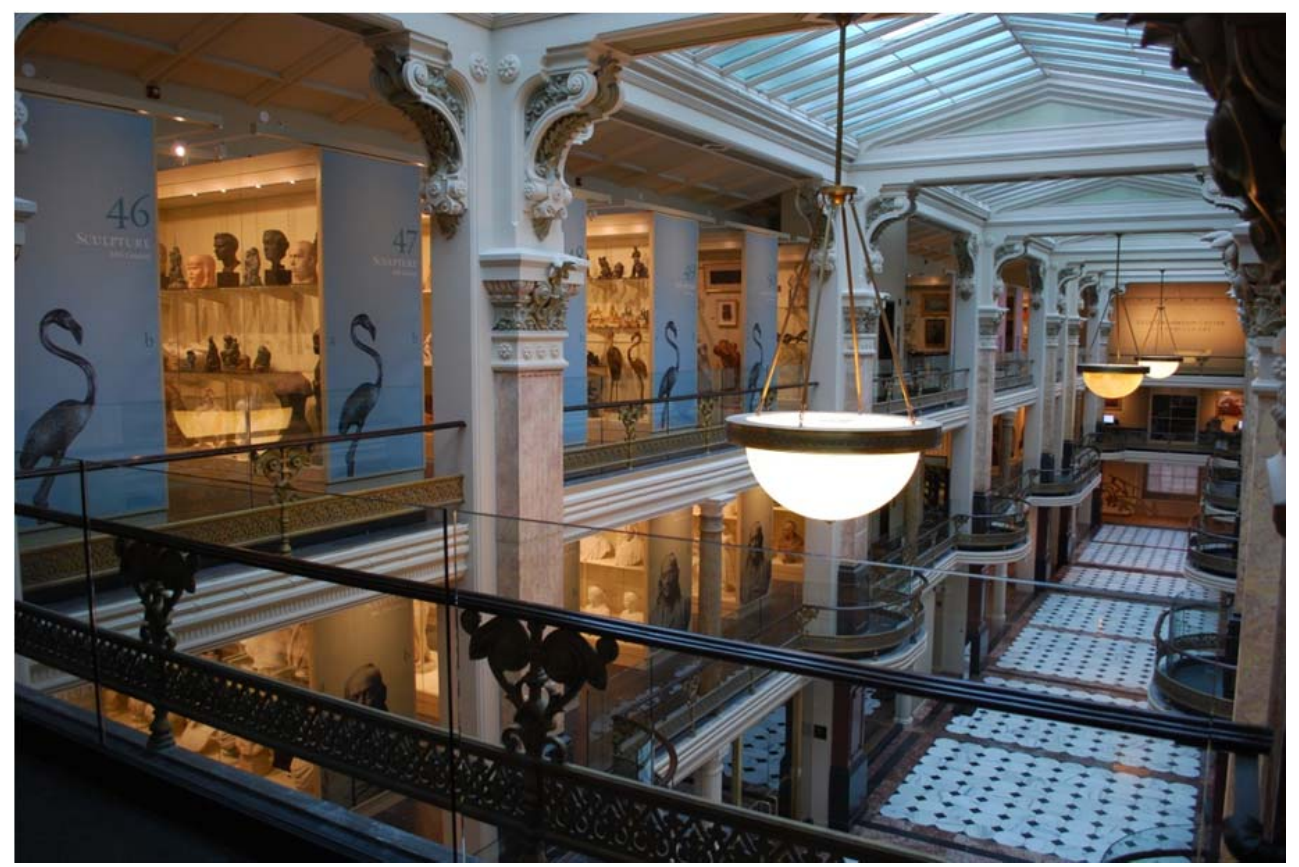

Figure 18. The Luce Center Gallery of the Smithsonian American Art Museum with storage galleries flanking the three-story center atrium. Photo courtesy of Smithsonian American Art Museum.

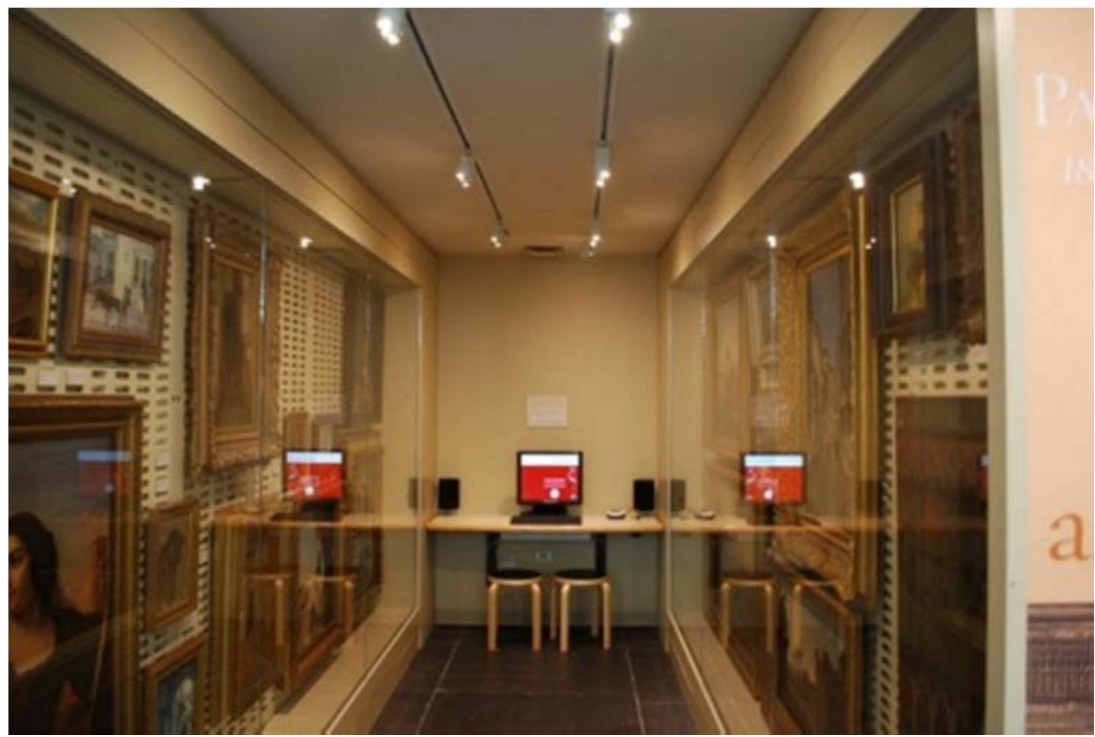

Figure 19. Typical display aisle of Luce Center Gallery with $8 \mathrm{ft} 0$ in. ceiling. Photo by Scott Rosenfeld. 
An electronic-transformer track luminaire is used for display lighting, equipped with a GE "Constant Color” 50W MR16 40 FL halogen lamp. The lighting system in the Luce Center Gallery is controlled by a Lutron dimming system, with a reverse phase ("ELV" or "trailing edge") dimmer for this type of load.

Knowing that electronic transformers and dimmers can introduce incompatibilities into the lighting system, the lighting designer was willing to reprogram the dimming system so that it delivered "full output” or was "off," but was never a significant phase-cut waveform to the replacement lamps. However, little could be done about the electronic transformer, since magnetic transformers are usually larger than the housings designed for electronic transformers. (Size was critical because the existing MR16 fixtures, seen in Figure 20, were specially built to allow the glass case doors to open without hitting the lighting fixtures.) The lighting designer was determined to find 12V LED replacement lamps compatible with electronic transformers.

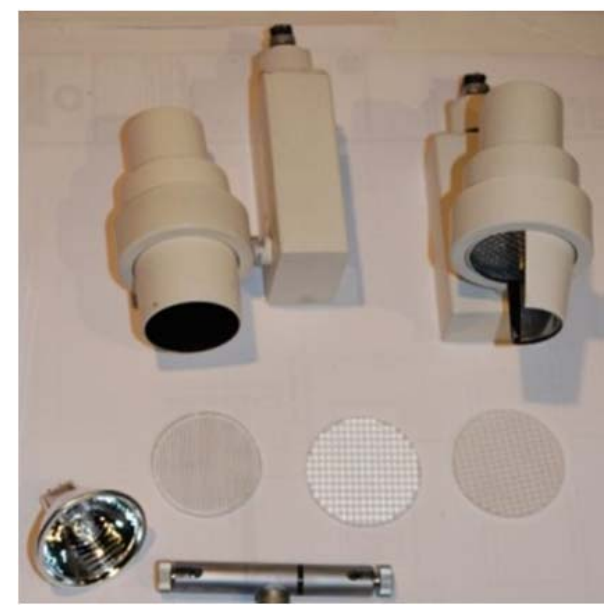

Figure 20. MR16 track heads with electronic transformers used in Luce Center. Photo by Scott Rosenfeld.

According to the manufacturer, the 50W MR16 halogen lamp delivers about 750 lumens, with CBCP of 1700 cd. In 2011, there were no true 50W-equivalent MR16 LED replacement lamps that also offered $3000 \mathrm{~K}$ color and the needed color spectrum. At best, some came close to a 35W equivalent. However, the lighting designer was also willing to increase the number of track heads to compensate for the reduced light output per LED lamp as long as a beam angle of $40^{\circ}$ or more could be obtained. Over the course of the year, the lighting designer tested products from 10 manufacturers or more. While every product showed differences, the following list of unsatisfactory characteristics ultimately prevented LED MR16 lamps from being used:

- Beam distribution: Only one manufacturer offered an MR-16 with a wide angle $52^{\circ}$ beam angle. A beam angle of $40^{\circ}$ or greater was necessary to provide an adequate wallwash without additional lensing that would reduce illuminance and efficacy, or block air flow in the luminaire. Unfortunately, the next widest available beam angle was only $36^{\circ}$.

- Color appearance: The color appearance of some LEDs did not match that of the halogen lighting in adjacent cases. Some LED MR16 products had a yellowish, bluish, or pinkish cast, compared to the incumbent halogen. (In fact, the halogen lamps tended to appear slightly green compared to the LED lamps, but the museum staff was trying to maintain the appearance of the halogen lamps.) 
- Low lumen output: Several LED lamps produced less light than a 20W halogen lamp (approximately 300 lumens), and therefore would have required more than twice the number of existing track heads.

- Flicker: Several lamps produced a noticeable flicker when powered by the electronic transformer in the track head. The flicker was obvious to some observers, especially when their eyes would scan across the selection of art works in the display cases. The lighting designer relied on two tests: (1) he would rapidly wave a pencil in the light and look for a strobe effect, and (2) he used a spinning top with a printed pattern that would appear as a striped band when spun under the flickering test light. (The top was originally intended to differentiate magnetic and high-frequency electronic fluorescent ballasts.)

One manufacturer's MR16 lamps satisfied the color, lumen output, and beam angle requirements, and the manufacturer provided samples that did not flicker. However, the manufacturer was not able to ship larger quantities (of 100 lamps) that reliably performed without flicker.

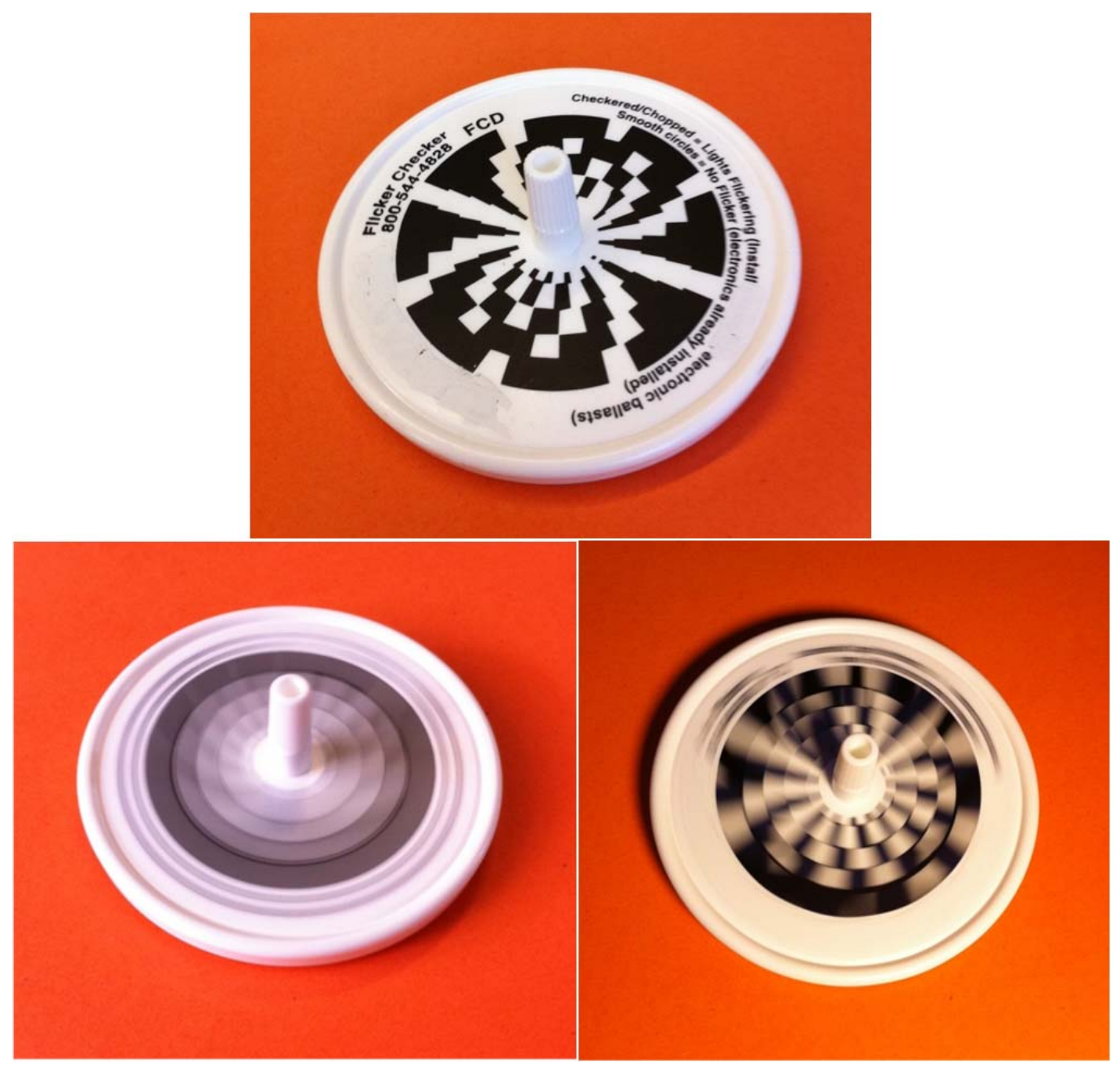

Figure 21. Flicker checker top. The top image shows it at rest, the bottom left image shows the top spinning under LED sources with very low modulation (i.e., minimal flicker); the bottom right image shows the top spinning under a source with very high modulation (i.e., pronounced flicker). Photos by PNNL. 
Despite several iterations with LED replacement lamp manufacturers to correct the behavior, there was no completely successful lamp.

The lighting designer decided to abandon the effort until a new generation of lamps is engineered to solve the compatibility problems among dimmer, transformer, and the driver built into the LED lamp. The museum had hoped to phase-in the installation of LED lighting, retrofitting approximately $1 / 4$ of the room at a time. After extensive testing, it appears unlikely that a retrofit lamp will be found that precisely matches the color of halogen MR16 lamps; therefore, it is expected that all 780 lamps will need to be changed out at the same time to achieve a consistent color and lighting effect throughout the gallery.

\subsection{The Lighting Designer's Wish List}

Lighting designer Scott Rosenfeld's experience with the many types and manufacturers of LED replacement lamps on this project prompted a list of observations and needed products for museum lighting.

1. Observation: Lamps with a chromaticity that matches their incandescent equivalent is the mandate for all areas of the Smithsonian American Art Museum. However, other museums should consider choosing their CCT based on application. Black and white photography may benefit from color temperatures in the $3000-4000 \mathrm{~K}$ range to render the whites as "white" rather than "amber." Changing CCTs between galleries should be done with care since the effect will be noticeable, especially in fine art museums. The lighting of fine art requires a curatorial opinion: a strong case can be made for warm ( 2850 CCT) or neutral light $(<4000 \mathrm{~K})$. (However, Rosenfeld has been unable thus far to match daylight CCTs ( $>4000 \mathrm{~K})$ on fine art in rooms without daylight. He postulates that at the low illuminance required for light sensitive material (50-200 lux), the Western viewing audience finds the cool light to look odd or out-of-place when there is no obvious daylight reference.)

2. Needed: MR16 LED replacement lamps that do not flicker or drop in light output when used in luminaires with electronic transformers.

3. Needed: LED replacement lamps with beam angles less than $8^{\circ}$. There is a special need for lamps to replace the 25W PAR36 5.5V (4º) lamp.

4. Needed: AR111 LED retrofit lamps. As of this writing there are no products with comparable narrow beam angles or intensities on the market.

5. Needed: High-lumen PAR38 LED replacement lamps capable of replacing 250W PAR38 $30^{\circ}$ flood lamps.

6. Needed: MR16 LED replacement lamps with wide distributions, between $30^{\circ}$ and $60^{\circ}$ beam angles.

7. Needed: Higher intensity MR16 lamps capable of use with asymmetric lenses.

8. Wanted: More lamps with built-in dimming ability, so that a single lamp can be used at different intensity levels. 
9. Wanted: Lamps with built-in beam angle adjustment; either an LED module with interchangeable optics, or an LED module paired with an adjustable condensing lens.

10. Wanted: Durable film color filters that won't fade in close proximity to LED sources. These filters (such as 1/8 and 1/4 CTO (color temperature orange), CTS (color temperature straw), and minus green) can be used to achieve slight color shifts when needed.

\subsection{Energy Comparison}

The energy comparison is based on the Early Modernism Gallery only, since that gallery's lighting system was completely changed over to LED replacement products. The LED lighting system with 82 track heads uses $5832 \mathrm{kWh}$ per year, compared to 21,316 kWh for a savings of $72 \%$ from the original halogen/incandescent lighting system. At $\$ 0.14$ per kWh, the electricity for the gallery space's display lighting costs the Smithsonian American Art Museum \$2,984 per year using their halogen and incandescent lamps, compared with only \$816 using the LED replacement lamps. Table 5 summarizes the energy and economic comparison, and shows the corresponding reductions in annual emissions based on the electrical generation fuel mix for Washington, DC.

\subsection{Life-Cycle Cost Analysis}

The higher upfront costs of LED retrofit lamps are frequently offset by reduced electricity and maintenance costs over the long life of the LED lamps. The LED integral replacement lamps used in this retrofit project are on automatic control circuits, operated 11.5 hours per day, 365 days per year for a total of 4197 hours per year, plus hours for special events or special maintenance, which increases the operation hours to 4500 hours per year. The LED replacement lamps have a claimed useful $\left(L_{70}\right)$ life of 25,000 to 35,000 hours, or 5.6 years at this usage rate, assuming the more conservative 25,000 value. The incumbent halogen/incandescent lamps have an expected average life of 1000 to 4000 hours (the point at which $50 \%$ of the lamps are expected to have failed), or about 3 to 11 months.

This economic analysis uses the National Institute of Standards and Technology's Building LifeCycle Cost (BLCC) software, ${ }^{1}$ which calculates the life-cycle costs for energy conservation projects. The BLCC software was used to model the present value life-cycle cost of the (82) LED lamps, in comparison to the life-cycle costs had the museum's original 86 halogen/incandescent lamps been installed. Both the halogen and LED scenarios are based on a 10-year analysis of each system's respective costs. This retrofit project is evaluated in terms of annualized spot-relamping costs (including labor at \$7.20 per lamp) and projected 10-year energy costs, taking into account projected real fluctuations in energy prices. A 3.0\% discount rate was assumed. Full details can be found in Appendices A through C.

In the United States, commercial electricity prices vary greatly from state to state and region to region. As a reference point, the U.S. Energy Information Administration publishes the Average Retail Price of Electricity to Ultimate Customers by End-Use Sector by State. ${ }^{2}$ The national average retail price of electricity to ultimate commercial customers in May 2011 was approximately $\$ 0.10 / \mathrm{kWh}$, and commercial electricity prices ranged from a high of $\$ 0.284 / \mathrm{kWh}$ in Hawaii to a low of $\$ 0.066 / \mathrm{kWh}$ in Utah. The melded retail rate that the Smithsonian American Art Museum pays the local utility is above

\footnotetext{
${ }^{1}$ Available online at http://www1.eere.energy.gov/femp/information/download blcc.html.

${ }^{2}$ Available online at http://www.eia.gov/cneaf/electricity/epm/chap5.pdf .
} 
the national average at $\$ 0.14 / \mathrm{kWh}$. In general, LEDs are more likely to be economically viable in places where electricity costs are high enough that the energy savings they generate contribute significantly to paying back the high initial cost of LED products.

BLCC comparisons are based on "contractor-level" commercial lamp prices as reported by the Smithsonian American Art Museum, and confirmed by an online search of comparable prices. The LED lamps cost $\$ 30$ to $\$ 75$ each at the time of this study, replacing halogen/incandescent lamps that cost $\$ 4.50$ to $\$ 8.00$ each. No labor was included in the initial installation cost of the BLCC model because labor would be identical for both lamp types. Spot relamping was assumed for all subsequent lamp changes.

While the LED lamps are not expected to require any maintenance or to fail during the 10 years of life-cycle analysis, to build a conservative scenario, GATEWAY assumed an annual lamp replacement value of

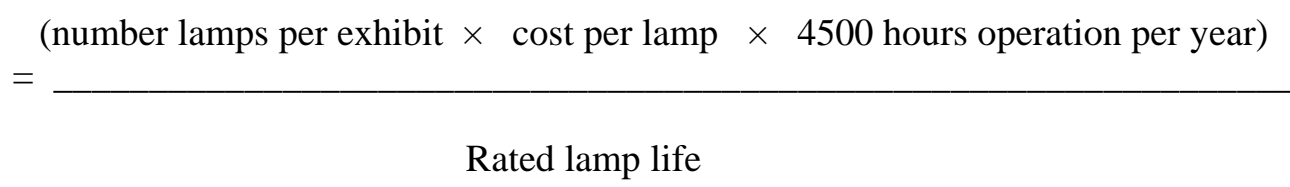

The museum's annualized halogen/incandescent lamp replacement cost for the Early Modernism Gallery is $\$ 2,757$ per year, including labor, while the LED PAR38 lamp annualized replacement cost is \$1,116 (see Appendix A).

\subsection{Payback Horizons and Economic Feasibility}

Table 5 summarizes the input data and life-cycle cost, energy, and emissions analysis for the incumbent halogen lamps and the replacement LED lamps, based on a 10-year operation in the museum. 
Table 5. Life-cycle cost input and comparative data for incumbent halogen/incandescent lamping in the Early Modernism Gallery. Analysis includes estimated labor costs for relamping.

\begin{tabular}{|c|c|c|}
\hline & $\begin{array}{c}\text { Incumbent } \\
\text { halogen/Incandescent } \\
\text { lamping of gallery using } \\
86 \text { lamps of } 7 \text { types }\end{array}$ & $\begin{array}{l}\text { LED replacement lamping of } \\
\text { gallery using } 82 \text { lamps of } \\
4 \text { types }\end{array}$ \\
\hline Initial Capital Costs for All Components & $\$ 466$ & $\$ 5,610$ \\
\hline Average Annual Electrical Energy Usage & 21,316.5 kWh & $5832 \mathrm{kWh}$ \\
\hline Average Electricity Cost per kWh & $\$ 0.14$ & $\$ 0.14$ \\
\hline First Year Energy Consumption Cost & $\$ 2,984.31$ & $\$ 816.48$ \\
\hline Study Period & 10 years & 10 years \\
\hline Discount Rate & $3.00 \%$ & $3.00 \%$ \\
\hline Discounting Convention & End-of-year & End-of-year \\
\hline Present Value (PV), Energy Consumption Costs & $\$ 26,213$ & $\$ 7,172$ \\
\hline Annual Value, Energy Consumption Costs & $\$ 3,073$ & $\$ 841$ \\
\hline Present Value, Relamping and Lamp Cost & $\$ 23,515$ & $\$ 9,521$ \\
\hline Annual Value, Relamping and Lamp Cost & $\$ 2,757$ & $\$ 1,116$ \\
\hline Present Value, Total Life-Cycle Cost & $\$ 50,193$ & $\$ 22,302$ \\
\hline Annual Value, Total Life-Cycle Cost & $\$ 5,885$ & $\$ 2,615$ \\
\hline \multicolumn{3}{|c|}{ Total Annual Emissions } \\
\hline $\mathrm{CO}_{2}$ & $25,237 \mathrm{~kg}$ & $6,905 \mathrm{~kg}$ \\
\hline $\mathrm{SO}_{2}$ & $84 \mathrm{~kg}$ & $23 \mathrm{~kg}$ \\
\hline NOx & $38 \mathrm{~kg}$ & $10 \mathrm{~kg}$ \\
\hline \multicolumn{3}{|c|}{ Comparative PV Data over 10-Year Study Period for LED Lamping vs. Halogen/Incandescent Lamping } \\
\hline Net Energy Savings from LED Lamping (PV) & Baseline & $\$ 19,041$ \\
\hline Net Savings from LED Lamping (PV) & Baseline & $\$ 27,891$ \\
\hline Savings-to-Investment Ratio & Baseline & 6.42 \\
\hline Adjusted Internal Rate of Return & Baseline & $24.05 \%$ \\
\hline Estimated Simple Payback Occurs in Year & Baseline & 2 \\
\hline
\end{tabular}

In this gallery space, the lighting system with 82 LED replacement lamps compares favorably against the original system with 86 halogen/incandescent lamps, since the higher initial cost of the LED is recovered in the second year of operation. At $\$ 0.14 / \mathrm{kWh}$ melded $^{3}$ electric rate, the total present value (PV) energy savings are $\$ 19,041$, and the total PV life-cycle cost savings are $\$ 27,891$.

Table 6 reports the present-value annual energy cost, total life-cycle cost, and payback periods for a range of electric rates, assuming the lamp costs remain fixed at their present costs. Higher utility rates yield greater cost savings and reduce payback periods.

Table 6. Comparative present value cost and energy of the LED lamps over 10-year analysis period, according to average electrical rate. Simple payback values are compared to the baseline halogen/incandescent lamping. Note that simple payback periods are shorter when energy prices are higher.

\begin{tabular}{lcccc}
\hline & \multicolumn{4}{c}{ Average cost of electricity } \\
\hline PV Energy Consumption Cost & $\$ 0.06 / \mathrm{kWh}$ & $\$ 0.12 / \mathrm{kWh}$ & $\$ 0.18 / \mathrm{kWh}$ & $\$ 0.24 / \mathrm{kWh}$ \\
Total PV Life-cycle Cost & $\$ 8,160$ & $\$ 16,321$ & $\$ 24,481$ & $\$ 32,642$ \\
Simple Payback & $\$ 17,010$ & $\$ 25,170$ & $\$ 33,331$ & $\$ 41,491$ \\
\hline
\end{tabular}

\footnotetext{
${ }^{3}$ The melded (or blended) electric rate is the average rate charged by the utility per kilowatt-hour, including time-of-
} use rate variations, demand charges, taxes, and fees. 
There are many factors to take into account in determining whether an LED system is cost-effective for a given site. This report focuses only on the initial investment, energy, and maintenance costs. In general, while their initial cost premium remains high, LED lighting systems can be cost-effective when electric utility rates are higher than average, hours of operation are long, and labor costs for relamping are high. Other factors could also affect the calculation of value and payback, such as embedded energy cost or the cost of lamp disposal and increased waste. At this point, these factors are difficult to quantify and vary according to location, so they are not included here.

\subsection{Lessons Learned for Museum Lighting}

\section{It is still critical to evaluate the LED lamps in person during the selection process}

Although documentation of color metrics can help narrow down the options, it is important to mock up the light sources with similar light levels, similar paint finishes, and on similar artwork in a test gallery. There is no substitute for the human eye in spaces with critical seeing applications.

\section{LED replacement lamps may not work on a one-to-one conversion from incandescent lamps.}

The light output and beam characteristics are similar, but seldom identical, to the lamp being replaced, so in a museum the designer should expect to relamp and re-aim multiple luminaires lamped with multiple types of LED replacement lamps in order to produce the ideal pattern of light on the objects.

\section{If carefully chosen, LED replacement lamps can deliver an equivalent appearance of artwork, so similar that the viewing audience may not notice that the light source is different}

LEDs are now available with a warm-color continuous spectrum that is remarkably similar to that of halogen lamps. This gives designers, curators, and conservators a new tool to illuminate critical museum objects, with a dramatic reduction in power and heat. Accessories such as louvers, cross-baffles, snoots, and lenses help conceal the direct view of the LED on the lamp face. This controls glare and prevents drawing attention to the different lamp appearance.

\section{Spectral Power Distribution (SPD) data is required for all lamps considered for museum applications}

LEDs with a CCT of more than 4000K will likely increase the damage potential of the lighting source beyond the energies present in incandescent lighting and therefore should be carefully evaluated by the museum's conservation department before installation. All lamps considered for museum use should offer an LM-79 report, complete with detailed SPD data.

\section{Wider LED replacement lamp offerings are needed}

LED replacement lamps are still only available in a very narrow range of light distributions and lumen levels. Museum lighting, like many other applications, would benefit from a wider range of offerings, including lower-output options. Manufacturers should not automatically assume that because a 
lamp can deliver more light with a new chip, the older, lower-output version is no longer wanted. If lower-lumen lamps were available, fewer screens would be needed to reduce light levels on sensitive art, reducing energy use.

\section{Incompatibility among drivers, transformers, and dimmers can result in flicker}

Human sensitivity to flicker varies widely. Flicker may be invisible, an annoyance, a source of discomfort and distraction, or a potential health hazard for different individuals. To avoid introducing flicker, test the specific replacement lamp with the specific installed transformer and dimmer. Until there is a reliable flicker metric, use a flicker-checker top or rapid waving of a pencil under the light source to pick up significant strobe effects that indicate the presence of flicker.

\section{LEDs have thermal issues that can complicate installations.}

Some lamps have thermistors built into the electronics, which reduce light output and wattage if the lamp overheats. While this protects the lamp, it means the designer must wait to finalize lamping and aiming until the lamps have dropped to their protected level. The Smithsonian had no problems using lamps with thermistors because these lamps demonstrated consistent dimming behavior over time and from lamp to lamp.

\section{Some replacement lamps require air circulation or conduction to wick heat away from the LED chips.}

When used in enclosed fixtures or track heads with solid backs and glass filters on the front, air flow is restricted and the lamp may overheat. Open-back or gimbal-ring-type track heads may be a good choice for LED replacement lamps because the open design helps keep the lamp cool.

\section{Energy savings from LED replacement lamps are significant when compared to halogen incumbents}

The power reduction from changing to LEDs in the Early Modernism Gallery was more than $72 \%$. Economic payback rates depend on several factors, including a significant power difference between the incumbent system and the replacement system similar to this one. The simple payback occurs in year 2 of operation (specifically, 1 year 4 months) because of the above-average power rates in the Washington, DC area (14 cents per $\mathrm{kWh}$ ), in spite of the high cost of the LED replacement lamps. In general, payback times will be shorter when

- the difference in power draw between the incumbent lighting system and the replacement LED system is significant (e.g., more than a $50 \%$ reduction);

- electric rates are higher (e.g., greater than the U.S. average \$0.10/kWh melded rate);

- labor costs for relamping are high because of hard-to-reach locations, areas where skilled labor is costly, the need for access outside of normal work crew hours, spaces with limited access because of the need for a special security clearance, spaces with clean room requirements, etc.; and

- hours of operation are extensive (e.g., much longer than 40 hours per week).

Higher values in any one of these factors will shorten payback times and make the project more economically viable. 


\subsection{References for Museum Lighting and Artifact Conservation}

Druzik JR and SW Michalski. 2011. Guidelines for Selecting Solid-State Lighting for Museums. Canadian Conservation Institute and the Getty Conservation Institute. Accessed March 6, 2012 at http://www.getty.edu/conservation/our_projects/science/lighting/lighting_component8.html (last updated December 2011).

CIE Publication 157:2004, Control of Damage to Museum Objects by Optical Radiation. International Commission on Illumination, Vienna, Austria.

IES RP-30, Museum and Art Gallery Lighting: A Recommended Practice (in press). Illuminating Engineering Society, New York.

Cuttle C. 2007. Light for Art's Sake: Lighting for Artworks and Museum Displays. ButterworthHeinemann, Oxford.

Weintraub, Steven. 2010. Comments regarding LEDs and the risk to light sensitive materials. American Institute for Conservation website, accessed April 13, 2012 at http://www.conservation-

us.org/_data/n_0001/resources/live/Response\%20from\%20Steve\%20Weintraub.pdf.

The Canadian Conservation Institute maintains a website with information for building a comprehensive lighting policy for museums:

SW Michalski. 2011. Light, Ultraviolet, and Infrared. The Canadian Conservation Institute. Accessed March 6, 2012 at http://www.cci-icc.gc.ca/caringfor-prendresoindes/articles/10agents/chap08-eng.aspx (last updated August 2, 2011). 


\section{Appendix A: Smithsonian American Art Museum Early Modernism Gallery Input Data for Life-Cycle Cost Analysis}

Rose Gallery, Smithsonian American Art Museum - Input values for Life Cycle Cost Analysis Incumbent halogen Lamping, LED Lamping

\begin{tabular}{|c|c|c|c|c|c|c|c|c|c|c|c|c|c|c|c|}
\hline 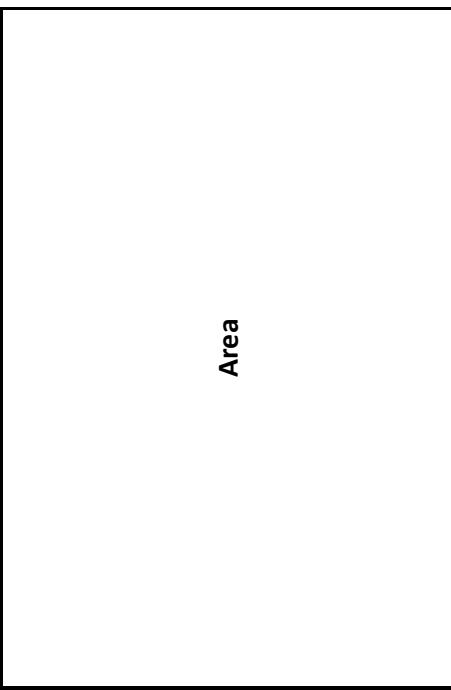 & 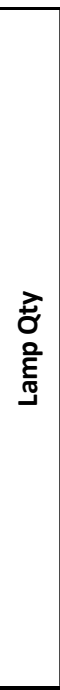 & 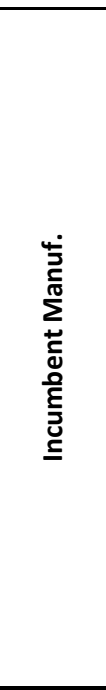 & $\underset{\text { Е }}{\stackrel{0}{\Xi}}$ & 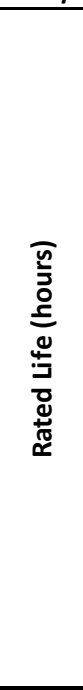 & $\underbrace{ \pm}_{3}$ & 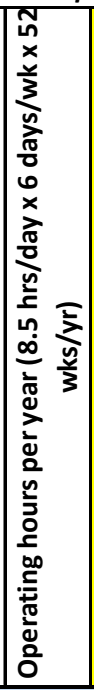 & 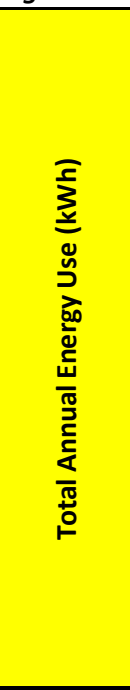 & 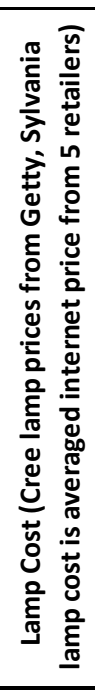 & & 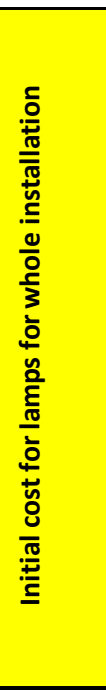 & 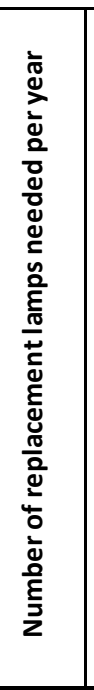 & 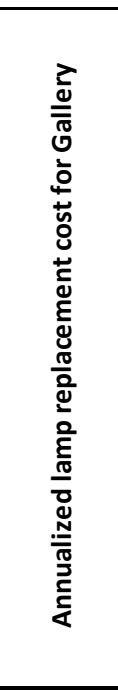 & 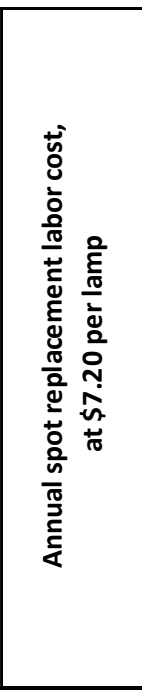 & 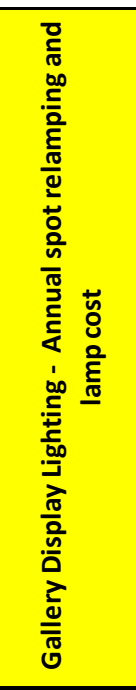 & 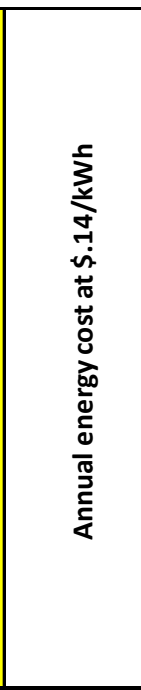 \\
\hline \multicolumn{16}{|l|}{ Halogen/incand lamping } \\
\hline VNSP to spotlight artwork & 26 & GE & 50PAR36/VNSP & 1000 & 50 & 4500 & 5850.00 & $\$ 5.50$ & $\$$ & 143.00 & 117.0 & $\$ 643.50$ & $\$ 842.40$ & $\$ 1,485.90$ & $\$ 819.00$ \\
\hline NSP to spotlight artwork & 2 & $\mathrm{GE}$ & 50PAR36/NSP & 2000 & 50 & 4500 & 450.00 & $\$ 5.50$ & $\$$ & 11.00 & 4.5 & $\$ 24.75$ & $\$ \quad 32.40$ & $\$ \quad 57.15$ & 63.00 \\
\hline wide flood signage & 3 & $\mathrm{GE}$ & 50PAR36/WFL & 2000 & 50 & 4500 & 675.00 & $\$ 5.50$ & $\$$ & 16.50 & 6.8 & $\$ 37.13$ & $\$ \quad 48.60$ & $\$ 85.73$ & 94.50 \\
\hline Pin spot to spotlight artwork & 10 & $\mathrm{GE}$ & 25PAR36 & 2000 & 25 & 4500 & 1125.00 & $\$ 8.00$ & $\$$ & 80.00 & 22.5 & $\$ 180.00$ & $\$ 162.00$ & $\$ 342.00$ & $\$ \quad 157.50$ \\
\hline Spotlighting artwork & 6 & PHILIPS & 50PAR30/NSP & 2000 & 50 & 4500 & 1350.00 & $\$ 5.50$ & $\$$ & 33.00 & 13.5 & $\$ 74.25$ & $\$ 97.20$ & $\$ 171.45$ & $\$ \quad 189.00$ \\
\hline Floor lighting & 7 & $\mathrm{GE}$ & 75PAR30/WFL & 2000 & 75 & 4500 & 2362.50 & $\$ 4.67$ & $\$$ & 32.69 & 15.8 & $\$ 73.55$ & $\$ 113.40$ & $\$ 186.95$ & $\$ 330.75$ \\
\hline \begin{tabular}{|l} 
wall lighting (lamp is 75 watts @ 130v) \\
\end{tabular} & 32 & $\mathrm{GE}$ & 75 PAR30/35 & 4000 & 66 & 4500 & 9504.00 & $\$ 4.67$ & $\$$ & 149.44 & 36.0 & $\$ 168.12$ & $\$ 259.20$ & $\$ 427.32$ & $\$ 1,330.56$ \\
\hline TOTALS & 86 & & & & & & 21316.50 & & $\$$ & 465.63 & & & & $\$ 2,756.50$ & $\$ 2,984.31$ \\
\hline
\end{tabular}

\begin{tabular}{|c|c|c|c|c|c|c|c|c|c|c|c|c|c|c|c|c|c|}
\hline \multicolumn{18}{|l|}{ Replacement LED lamping } \\
\hline spotlight artwork & 25 & SOLAIS & LR30LN SPOT & 25000 & 18 & 4500 & 2025.00 & $\$ 75$ & $\$ 1,875.00$ & 4.5 & $\$ 337.50$ & $\$$ & 32.40 & & 369.90 & $\$$ & 283.50 \\
\hline Pinspot artwork & 12 & OPTILED & $\begin{array}{c}\text { Accent Radar } \\
3.5 \text { W MR-16 }\end{array}$ & 25000 & 3 & 4500 & 162.00 & $\$ 30$ & $\$ 360.00$ & 2.2 & $\$ 64.80$ & $\$$ & 15.55 & $\$$ & 80.35 & $\$$ & 22.68 \\
\hline spotlight artwork & 6 & SOLAIS & LR3OLN FLOOD & 25000 & 18 & 4500 & 486.00 & $\$ 75$ & $\$ \quad 450.00$ & 1.1 & $\$ 81.00$ & $\$$ & 7.78 & & 88.78 & $\$$ & 68.04 \\
\hline Floor lighting & 7 & SOLAIS & LR30LN FLOOD & 25000 & 18 & 4500 & 567.00 & $\$ 75$ & $\$ 525.00$ & 1.3 & $\$ 94.50$ & $\$$ & 9.07 & $\$$ & 103.57 & $\$$ & 79.38 \\
\hline wall lighting & 32 & SOLAIS & LR30LN FLOOD & 25000 & 18 & 4500 & 2592.00 & $\$ 75$ & $\$ 2,400.00$ & 5.8 & $\$ 432.00$ & $\$$ & 41.47 & $\$$ & 473.47 & $\$$ & 362.88 \\
\hline TOTALS & 82 & & & & & & 5832.00 & & $\$ 5,610.00$ & & & & & & $1,116.07$ & $\$$ & 816.48 \\
\hline
\end{tabular}





\section{Appendix B: Summary Life-Cycle Cost Calculations}

NIST BLCC 5.3-10: Summary LCC

Consistent with Federal Life Cycle Cost Methodology and Procedures, 10 CFR, Part 436, Subpart A

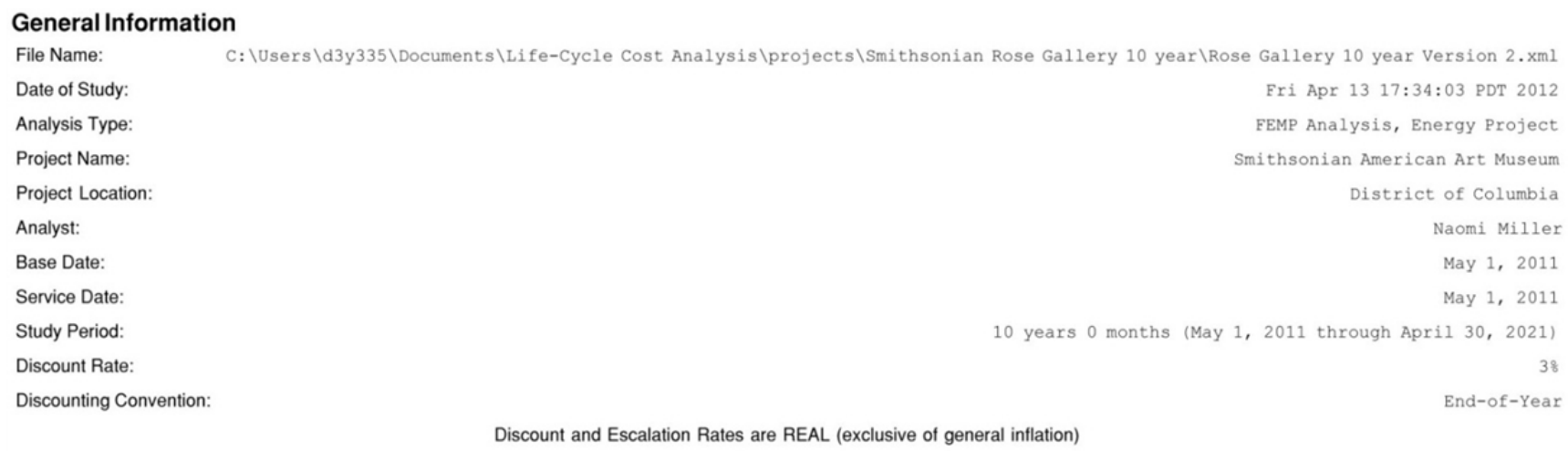

Discount and Escalation Rates are REAL (exclusive of general inflation)

$\begin{array}{lrr}\text { Alternative: Rose Gallery incumbent incand Ia } \\ \text { LCC Summary } & \text { Present Value } & \text { Annual Value } \\ \text { Initial Cost } & \$ 466 & \$ 55 \\ \text { Energy Consumption Costs } & \$ 26,213 & \$ 3,073 \\ \text { Energy Demand Costs } & \$ 0 & \$ 0 \\ \text { Energy Utility Rebates } & \$ 0 & \$ 0 \\ \text { Water Usage Costs } & \$ 0 & \$ 0 \\ \text { Water Disposal Costs } & \$ 23,515 & \$ 2,757 \\ \text { Annually Recurring OM\&R Costs } & \$ 0 & \$ 0 \\ \text { Non-Annually Recurring OM\&R Costs } & \$ 0 & \$ 0 \\ \text { Replacement Costs } & \$ 0 & \$ 0 \\ \text { Less Remaining Value } & ------------ \\ & \$ 50,193 & \$ 5,885\end{array}$

Alternative: Rose Gallery LED replacement lamps LCC Summary

Initial Cost Present Value Annual Value

Energy Consumption Costs

Energy Demand Costs

Energy Utility Rebates

Water Usage Costs

Water Disposal Costs

Annually Recurring OM\&R Costs

Non-Annually Recurring OM\&R Costs

Replacement Costs

Less Remaining Value

$\$ 5,610 \quad \$ 658$

$\$ 7,172 \quad \$ 841$

$\$ 0 \quad \$ 0$

\$0 \$0

\$0 \$0

$\$ 0 \quad \$ 0$

$\$ 9,521 \quad \$ 1,116$

\$0 \$0

\$0 \$0

\$0 \$0

Total Life-Cycle Cost

$\$ 22,302 \quad \$ 2,615$





\title{
Appendix C: Comparative Analysis of Life-Cycle Cost
}

NIST BLCC 5.3-10: Comparative Analysis

Consistent with Federal Life Cycle Cost Methodology and Procedures, 10 CFR, Part 436, Subpart A

Base Case: Rose Gallery incumbent incand lamps

Alternative: Rose Gallery LED replacement lamps

General Information

File Name:

C: $\backslash$ Users $\backslash$ d3y335 \Documents $\backslash$ Life-Cycle Cost Analysis $\backslash$ projects $\backslash$ Smithsonian Rose Gallery 10 year $\backslash$ Rose

Date of Study:

Gallery 10 year Version 2.xml

Project Name:

Fri Apr 13 17:44:42 PDT 2012

Project Location:

Smithsonian American Art Museum

Analysis Type:

District of Columbia

Analyst:

Base Date:

FEMP Analysis, Energy Project

Service Date:

Naomi Miller

Study Period:

May 1, 2011

May 1, 2011

Discount Rate:

10 years 0 months (May 1, 2011 through April 30, 2021)

Discounting

Convention:

End-of-Year

\author{
Comparison of Present-Value Costs \\ PV Life-Cycle Cost \\ Base Case Alternative Savings from Alternative \\ Initial Investment Costs: \\ Capital Requirements as of Base Date \\ $\$ 466 \quad \$ 5,610 \quad-\$ 5,144$ \\ Future Costs: \\ Energy Consumption Costs $\quad \$ 26,213 \quad \$ 7,172 \quad \$ 19,041$ \\ Energy Demand Charges \\ Energy Utility Rebates \\ Water Costs \\ $\$ 0$ \\ $\$ 0$ \\ $\$ 0$ \\ $\begin{array}{lll}\$ 0 & \$ 0 & \$ 0 \\ \$ 0 & \$ 0 & \$ 0\end{array}$ \\ Recurring and Non-Recurring OM\&R Costs \\ $\$ 23,515 \quad \$ 9,521$ \\ $\$ 13,994$ \\ Capital Replacements \\ Residual Value at End of Study Period \\ $\$ 0$ \\ $\$ 0$ \\ $\$ 0$ \\ $\$ 0$ \\ $\$ 0$ \\ Subtotal (for Future Cost Items) \\ $\$ 49,727 \quad \$ 16,692$ \\ $\$ 33,035$ \\ Total PV Life-Cycle Cost \\ $\$ 50,193 \quad \$ 22,302$ \\ $\$ 27,891$ \\ Net Savings from Alternative Compared with Base Case \\ PV of Non-Investment Savings $\quad \$ 33,035$ \\ - Increased Total Investment $\$ 5,144$ \\ Net Savings $\$ 27,891$ \\ Savings-to-Investment Ratio (SIR) \\ $\operatorname{SIR}=6.42$ \\ Adjusted Internal Rate of Return \\ AIRR $=24.05 \%$ \\ Payback Period \\ Estimated Years to Payback (from beginning of Service Period) \\ Simple Payback occurs in year \\ Discounted Payback occurs in year 2
}




\begin{tabular}{|c|c|c|c|c|}
\hline \multicolumn{5}{|c|}{$\begin{array}{l}\text { Energy Savings Summary } \\
\text { Energy Savings Summary (in stated units) }\end{array}$} \\
\hline Energy & -----Average & Annual & Consumption----- & Life-Cycle \\
\hline Type & Base Case & Alternative & Savings & Savings \\
\hline
\end{tabular}

\section{Energy Savings Summary (in MBtu)}

\begin{tabular}{|c|c|c|c|c|}
\hline Energy & ----Average & Annual & Consumption----- & Life-Cycle \\
\hline Tun & Base Case & Alternative & Savings & Savings \\
\hline Electricity & $n$ & $19.9 \mathrm{MBtu}$ & $52.8 \mathrm{MBtu}$ & $528.3 \mathrm{MB}$ \\
\hline
\end{tabular}

\begin{tabular}{|c|c|c|c|c|c|c|}
\hline \multicolumn{7}{|c|}{ Emissions Reduction Summary } \\
\hline Energy & -.---Average & Annual & & Emissions----- & & Life-Cycle \\
\hline Type & Base Case & Alternative & & Reduction & & Reduction \\
\hline \multicolumn{7}{|c|}{ Electricity } \\
\hline $\mathrm{CO} 2$ & $25,237.44$ & $\mathrm{~kg} 6,904.73$ & $\mathrm{~kg} 1$ & $18,332.71 \mathrm{k}$ & $\mathrm{kg} 1 \varepsilon$ & $33,301.98 \mathrm{~kg}$ \\
\hline $\mathrm{sO} 2$ & $83.66 \mathrm{r}$ & 22.89 & $\mathrm{~kg}$ & $60.77 \mathrm{k}$ & $\mathrm{kg}$ & $607.61 \mathrm{~kg}$ \\
\hline NOx & $37.76 \mathrm{r}$ & 10.33 & $\mathrm{~kg}$ & $27.43 \mathrm{k}$ & $\mathrm{kg}$ & $274.26 \mathrm{~kg}$ \\
\hline \multicolumn{7}{|l|}{ Total: } \\
\hline $\mathrm{CO} 2$ & $25,237.44$ & $\mathrm{~kg} 6,904.73$ & $\mathrm{~kg} 1$ & $18,332.71 \mathrm{k}$ & $\mathrm{kg} 18$ & $3,301.98 \mathrm{~kg}$ \\
\hline $\mathrm{sO} 2$ & 83.66 & 22.89 & $\mathrm{~kg}$ & $60.77 \mathrm{k}$ & $\mathrm{kg}$ & $607.61 \mathrm{~kg}$ \\
\hline NOx & 37.76 & 10.33 & $\mathrm{~kg}$ & $27.43 \mathrm{k}$ & $\mathrm{kg}$ & $274.26 \mathrm{~kg}$ \\
\hline
\end{tabular}





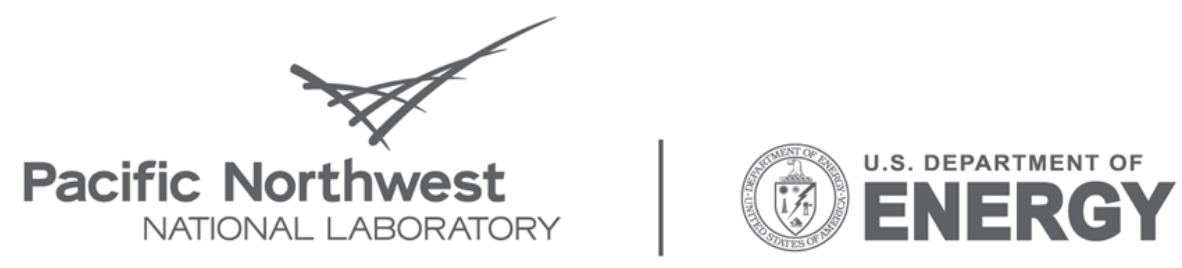

Proudly Operated by Battelle Since 1965

902 Battelle Boulevard

P.O. Box 999

Richland, WA 99352

1-888-375-PNNL (7665)

www.pnl.gov 